\title{
Jusepe Leonardo y la decoración de arquitecturas efímeras en la iglesia de Santa María la Real de la
}

\section{Almudena*}

\author{
Jusepe Leonardo and the Decoration of Ephemeral Architectures \\ in the Church of Santa Maria la Real de la Almudena
}

\section{José Luis Cueto Martínez-Pontrémuli ${ }^{1}$}

Museo Nacional del Prado

Resumen: Se documenta la participación de Jusepe Leonardo (Calatayud, 1601Zaragoza, ca. 1653) en la realización de pinturas para los monumentos de Semana Santa en la antigua iglesia de la Almudena de Madrid y se estudia el proceso de fabricación de estas arquitecturas desde 1632, en el que intervinieron diferentes maestros. A través de los pagos recogidos en los libros de cuentas de la fábrica de la iglesia, se añaden al catálogo del pintor dos nuevas obras, hoy perdidas, con los temas de la Flagelación de Cristo y la Oración en el huerto, encargadas para el monumento de 1633.

Palabras clave: Jusepe Leonardo; Santa María de la Almudena; monumento de Semana Santa; arquitectura efímera; Flagelación de Cristo; Oración en el huerto.

Abstract: In this paper we document the participation of Jusepe Leonardo (Calatayud, 1601-Zaragoza, ca. 1653) in the execution of paintings for the Holy Week monuments in the old church of Santa Maria de la Almudena (Madrid), as well as the manufacturing process of these architectures since 1632, in which different masters intervened. Through the payments registered in the church ledgers, we add two

\footnotetext{
* Deseo expresar mi agradecimiento a los doctores Ismael Gutiérrez Pastor y David García Cueto por su inestimable ayuda en la preparación de este artículo. También quiero agradecer a María Cristina Tarrero Alcón, directora del Museo de la Catedral de la Almudena, Juan Triviño Fernández, director del Archivo Diocesano de Toledo y al personal del Archivo Histórico Nacional, en especial a Almudena Pedrero Pérez, responsable del Departamento de Referencias, por su amabilidad y colaboración a lo largo de mi investigación. Por último, agradezco a los evaluadores de la revista por sus acertados comentarios y sugerencias.

1 (i) http://orcid.org/0000-0003-0429-2963
} 
works to the painter's catalogue, commissioned for the 1633 monument: the Flagellation of Christ and the Agony in the Garden, both works long since lost.

Keywords: Jusepe Leonardo; Santa Maria de la Almudena; Holy Week monument; ephemeral architecture; Flagellation of Christ; Agony in the Garden.

\section{Introducción}

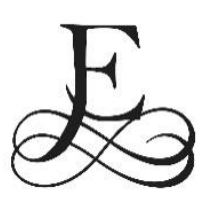

ntre las múltiples manifestaciones artísticas que conforman la denominada arquitectura efímera de la Edad Moderna, los monumentos de Semana Santa se diferencian por haber sido realizados con una clara voluntad de perdurar. Elaborados con armazones de madera, lienzos, escayolas y otros materiales ligeros, eran construidos pensando en la reutilización de sus estructuras y decoraciones durante el mayor periodo de tiempo posible. Año tras año se armaban en el interior de las iglesias para acoger, -a partir de la Missa in Coena Domini del Jueves Santo y hasta el día de Viernes Santo-, la reserva de la Eucaristía, dentro de un ambiente escenográfico pleno de alusiones a la Pasión y muerte de Cristo. Una vez concluida la celebración, las máquinas decorativas y tramoyas de Semana Santa se desmontaban y recogían en dependencias de la iglesia, esperando los arreglos y aderezos que al año siguiente ocultarían los deterioros ocasionados por sus reiterados traslados y manipulaciones.

Su particular naturaleza, a mitad de camino entre la arquitectura efímera y la vocación de permanencia, junto con la escasez de estudios monográficos hasta épocas bastante recientes, ha motivado que estas arquitecturas desmontables gocen tradicionalmente de una consideración menor. Esto contrasta con la importancia conferida a las edificaciones festivas diseñadas con motivo de entradas triunfales y proclamaciones de reyes, así como las exequias y túmulos funerarios, de fuerte tradición en los distintos territorios bajo el dominio de la Casa de Austria, que han recibido mayor atención por parte de la historiografía.

Bonet Correa, en su trabajo fundamental sobre la arquitectura efímera en España, destacó el carácter ambiguo, entre efímero y temporal, de los monumentos de Semana Santa, a los que dedicó una breve mención junto al resto de decoraciones provisionales diseñadas para festividades religiosas como el Corpus Christi, los traslados de reliquias, la canonización de santos, las procesiones y los altares callejeros ${ }^{2}$. Además de esta aproximación general, en las últimas décadas han visto la luz diferentes estudios sobre ejemplos concretos repartidos por toda la geografía española, muy

\footnotetext{
2 Antonio Bonet Correa, "La arquitectura efímera del Barroco en España", Norba, 13, (1993), pp. 23-70.
} 
numerosos en Galicia ${ }^{3}$, País Vasco ${ }^{4}$, Navarra ${ }^{5}$ y Aragón 6 , así como nuevas aportaciones sobre los monumentos de las catedrales de Barcelona7, Segovia8, Toledo -diseñado y realizado por Francisco Rizi con la colaboración de Carreño de Miranda, Escalante y Dionisio Mantuano ${ }^{9}$ - o Sevilla ${ }^{10}$. Estas investigaciones ayudan a sentar las bases de un conocimiento cada vez más amplio sobre las arquitecturas efímeras de Semana Santa en nuestro país. De todos ellos destaca, por su aparato crítico y teórico, la aportación de Calvo Ruata y Lozano López sobre el ámbito aragonés, con una definición del monumento, sus usos y funciones, distintas tipologías y principales programas iconográficos ${ }^{11}$.

En el caso madrileño cabe citar la tesis doctoral de Tarrero Alcón sobre la historia y el patrimonio artístico de la iglesia de Santa María la Real de la Almudena. En este trabajo, imprescindible para cualquier aproximación sobre el mencionado edificio y sus bienes artísticos, la autora expone la creación de arquitecturas efímeras en la iglesia, con especial detenimiento en la preparación de la fiesta del Corpus Christi, ofreciendo también importantes

\footnotetext{
${ }^{3}$ Fernando González Suárez, "Las pinturas del monumento de Semana Santa de Beade", Porta da aira, 1, (1988), pp. 121-129; Fernando González Suárez, "Notas sobre las pinturas del monumento de Semana Santa en Beade", Porta da aira, 2, (1989), pp. 233-235; Francisco Xavier Novo Sánchez, "El monumento de Semana Santa de la catedral de Tui ¿arte efímero?", en Las artes y la arquitectura del poder, coord. Víctor Mínguez Cornelles, (Castellón de la Plana: Universitat Jaume I, 2013), pp. 2653-2672.

4 Julen Zorrozua Santisteban, "El monumento de Semana Santa de Santa María de Bermeo (Bizkaia)", Ondare, 21, (2002), pp. 257-272; Fernando R. Bartolomé García, "Patrimonio recuperado: el monumento de Semana Santa de la Iglesia de Heredia", Akobe, 4, (2003), pp. 64-68.

${ }^{5}$ Pedro Luis Echeverría Goñi, "Los monumentos o perspectivas en la escenografía del siglo XVIII de las grandes villas de la Ribera estellesa", Príncipe de Viana, 51, 190, (1990), pp. 517-532; Sara González Bravo, "En torno a los monumentos de Semana Santa. El Barroco en Navarra", Príncipe de Viana, 77, 265, (2016), pp. 641-660.

${ }^{6}$ Juan Francisco Esteban Lorente, "La capilla de San Marcos y el monumento de Semana Santa de La Seo de Zaragoza", Cuadernos de investigación: Geografía e historia, 2, 1, (1976), pp. 97-104; María del Carmen Morte García, "Monumentos de Semana Santa en Aragón en el siglo XVI", Artigrama, 3, (1986), pp. 195-214; Juan Monzón Gasca, "Un proyecto de realidad aumentada para la difusión de la capilla del monumento de La Seo de Zaragoza: aplicación de técnicas de documentación gráfica y geométrica basadas en la ingeniería inversa", Ars \& Renovatio, 3, (2015), pp. 166-191; María Belén Ibáñez Abella, "Los cantorales y la librería del Coro en la Seo de Zaragoza: nuevas aportaciones documentales para el estudio de la reforma de la capilla de San Marcos y el monumento, a comienzos del siglo XVIII", Artigrama, 34, (2019), pp. 357-390.

7 Joan Bosch i Ballbona y Carles Dorico i Alujas, "El monument de Setmana Santa de la catedral de Barcelona, de 1735", D'art, 17, (1992), pp. 253-260; Santiago Mercader Saavedra, "Descubiertas las esculturas del antiguo monumento de Semana Santa de la catedral de Barcelona (1735)" en Congreso Internacional Imagen Apariencia, 2008, (Murcia: Universidad de Murcia, 2009).

8 María Jesús Quesada, "El monumento de Semana Santa de la catedral de Segovia", Estudios segovianos, 44, 101, (2001), pp. 303-320.

9 Juan Nicolau Castro, "Precisiones documentales sobre el monumento barroco de la catedral de Toledo y un dibujo madrileño del último tercio del siglo XVII", Archivo español de arte, 62, 246, (1989), pp. 216219; Amelia López-Yarto Elizalde, "El esplendor de la liturgia eucarística: el monumento y el arca del Jueves Santo de la catedral de Toledo", en Estudios de platería: San Eloy 2006, coord. Jesús Rivas Carmona, (Murcia: Universidad de Murcia, 2006), pp. 379-400; Eduardo Lamas-Delgado, "Monumento de Semana Santa de la catedral de Toledo, h. 1668", en I segni nel tempo. Dibujos españoles de los Uffizi, dir. Benito Navarrete Prieto, (Madrid-Florencia: Fundación Mapfre-Gallerie degli Uffizi, 2016), pp. 208209, no 96.

10 José Antonio García Hernández, "Las imágenes escultóricas del monumento de la catedral de Sevilla en la renovación de 1688-1689", Atrio, 1, (1989), pp. 43-60; José Antonio García Hernández, "El montaje del monumento eucarístico de la catedral de Sevilla en 1692", Atrio, 2, (1990), pp. 71-80; Alfredo J. Morales, "Un dibujo del monumento de la catedral de Sevilla por Lucas Valdés", Laboratorio de Arte, 6, (1993), pp. 157-167.

11 José Ignacio Calvo Ruata y Juan Carlos Lozano López, "Los monumentos de Semana Santa en Aragón (siglos XVII-XVIII)", Artigrama, 19, (2004), pp. 95-137.
} 
datos sobre el monumento de Semana Santa a partir de la década de 1640, sin abordar la labor que tuvo Jusepe Leonardo en los años anteriores ${ }^{12}$.

Entre las principales aportaciones documentales sobre artistas que diseñaron y realizaron monumentos pascuales en Madrid destacan los trabajos de Barrio Moya y Puerta Rosell dedicados a Sebastián de Benavente y la traza del monumento del convento de Agustinas Recoletas de Santa Isabel ${ }^{13}$, aspecto que más tarde estudiaría en profundidad Cruz Yábar ${ }^{14}$, así como el artículo de Aterido Fernández sobre el monumento de José de Churriguera para el monasterio de la Encarnación ${ }^{15}$. Ambos ejemplos de monumentos documentados en Madrid se corresponden con la segunda mitad del siglo XVII: el de Sebastián de Benavente en el año 1667 y el de José de Churriguera en 1699. Hasta ahora, uno de los primeros monumentos de los que se tenía noticia en la villa y corte era el diseñado por Alonso Cano para el convento de San Gil, del que nos hablan Lázaro Díaz del Valle y Palomino ${ }^{16}$, y que Cruz Yábar sitúa entre los años 1638 y $1642^{17}$.

La documentación conservada en los libros de fábrica de Santa María de la Almudena, fechable entre 1632 y 1737, nos permite acercarnos, -dentro de las limitaciones que impone el seguimiento de unas cuentas y gastos-, al proceso anual de creación y remodelación de un monumento de Semana Santa desde los primeros años de la década de $1630^{18}$. A través del presente artículo se pretende documentar la elaboración y decoración de este tipo de arquitectura efímera en Madrid, con encargos a diferentes artistas y con especial atención al importante papel que desempeñó Jusepe Leonardo en los años 1632-1639.

\footnotetext{
12 María Cristina Tarrero Alcón, Santa María la Real de la Almudena: dos siglos y medio de arte e historia (1638-1868), tesis doctoral inédita, Universidad Complutense, (Madrid: 2007). Sobre las celebraciones del Corpus Christi en la Almudena véase pp. 73-93; sobre el monumento de Semana Santa véase pp. 6670.

13 José Luis Barrio Moya, "Sebastián de Benavente y el monumento de Semana Santa del convento de Agustinas Recoletas de Santa Isabel en Madrid", Recollectio: annuarium historicum augustinianum, 2526, (2002-2003), pp. 199-206; María Fernanda Puerta Rosell, "Noticias sobre la vida y obra de Sebastián de Benavente: monumento de Semana Santa para el convento de Santa Isabel de Madrid", Anales del Instituto de Estudios Madrileños, 43, (2003), pp. 553-566.

${ }^{14}$ Juan María Cruz Yábar, El arquitecto Sebastián de Benavente (1619-1689) y el retablo cortesano de su época, tesis doctoral, Universidad Complutense, (Madrid: 2013), pp. 381-384 principalmente. El autor atribuye también a Sebastián de Benavente el diseño del monumento de Semana Santa de la iglesia parroquial de San Juan en Madrid, que se construyó poco antes del de Santa Isabel y sirvió como modelo para este último (pp. 215-216).

15 Ángel Aterido Fernández, "Una nueva obra de José de Churriguera: el monumento de Semana Santa del Monasterio de la Encarnación", Anales del Instituto de Estudios Madrileños, 35, (1995), pp. 19-31.

16 David García López, Lázaro Díaz del Valle y las Vidas de pintores de España, (Madrid: Fundación Universitaria Española, 2008), pp. 331-332; Antonio Palomino de Castro y Velasco, El museo pictórico y escala óptica, III, El parnaso español pintoresco laureado, (Madrid: Aguilar, 1947), p. 987.

17 Cruz Yábar, Arquitecto Sebastián de Benavente, p. 383; José Manuel Cruz Valdovinos, "Encargos y clientes de Alonso Cano en la corte de Felipe IV", en Alonso Cano. La modernidad del siglo de oro español, (Madrid: Fundación Santander Central Hispano, 2002), pp. 85-86.

18 Archivo Histórico Nacional (AHN), Clero secular regular, libro 8249 (cuentas entre 1632 y 1677) y libro 8247 (cuentas entre 1677 y 1737 ).
} 


\section{La construcción y decoración de monumentos en la iglesia de Santa María de la Almudena (1632-1737)}

Las cuentas de la iglesia de Santa María recogen la creación de un monumento nuevo en el año $1632^{19}$, construido con una estructura de madera y organizado a base de columnas, arcos y numerosos paños de lienzo que fueron completamente decorados con pinturas. También destacaba, dentro de esta obra, el papel de la luz y los efectos visuales, a través del empleo de superficies doradas, velas y vidrio, que contribuían a generar una apariencia de magnificencia acorde con la conmemoración de los episodios de la Pasión y muerte de Cristo. En primer lugar se procedió a la construcción del armazón de madera, en el que intervinieron los carpinteros Juan de Baltierra, Manuel de Peralta, Domingo Rodríguez y Ambrosio de Cueles, junto al ensamblador Juan Bautista ${ }^{20}$. Los trabajos para la creación de esta estructura ocuparon a los carpinteros y al maestro ensamblador durante casi un mes. Se pagaron 224 reales por las maderas, tablas y alfarjías necesarias, con la justificación de que el gasto estaba bien empleado ya que "el monumento sirve para adelante" ${ }^{\prime 21}$. Se evidencia así la voluntad de la fábrica de la iglesia de hacer una edificación duradera, que pudiera ser reutilizable durante años sucesivos.

A continuación, se emplearon otros 206 reales en la compra de 86 varas de lienzo de diferentes precios para las pinturas que cubrirían las columnas y los $\operatorname{arcos}^{22}$. Para la realización de esta decoración se pagaron 440 reales a "Josephe Leonardo pintor, por él y sus ofiçiales, del tiempo que se ocuparon en pintar todo lo neçesario para el monumento de dicho año"23. También se pagaron 16 reales a un oficial de Jusepe Leonardo "por renobar la tramoya de luces del monumento y refrescar los colores y oropel y bidrio" 24 .

En efecto, los elementos lumínicos para ensalzar los aspectos visuales de la obra y generar una fuerte impresión en el espectador estaban muy presentes en la concepción general de los monumentos de Semana Santa. Entre los últimos pagos por el de 1632 encontramos "quarenta y nuebe reales que gastó en bidrio bufado y oropel", lográndose así superficies brillantes a través del dorado y espolvoreado de vidrio sobre algunas partes de la estructura, que reflejarían la luz de los candiles y velas ${ }^{25}$. En artilugios de iluminación se emplearon otros 16 reales, pagados por los "canones y

\footnotetext{
19 AHN, Clero secular regular, libro 8249, ff. 10v-13v.

$20 \mathrm{AHN}$, Clero secular regular, libro 8249, ff. 12-13. Sobre este ensamblador, citado en la documentación como Juan Baptista, cabe preguntarse si nos encontramos ante Juan Bautista Garrido, estrecho colaborador y amigo de Jusepe Leonardo (ver nota 76). Esta posibilidad se vería reforzada por la existencia de otro pago en el mismo libro de cuentas a un Juan Garrido, carpintero y ensamblador, que recibe 400 reales por la construcción de una cubierta de madera con remates para el púlpito de la iglesia (f. 24). No obstante, conviene tener presente que desde el año 1637 son constantes los pagos a Juan Baptista de San Agustín, ensamblador milanés, que en este año incorpora algunas tablas al monumento de Semana Santa (f. 85), y más tarde se conciertan con él las decoraciones del monumento nuevo de 1652.

${ }_{21} \mathrm{AHN}$, Clero secular regular, libro 8249, ff. $10 \mathrm{v}-11$ (cita en f. 11).

22 AHN, Clero secular regular, libro 8249, f. 11.

${ }^{23} \mathrm{AHN}$, Clero secular regular, libro 8249, f. 13.

${ }^{24} \mathrm{AHN}$, Clero secular regular, libro 8249, ff. 13-13v.

$25 \mathrm{AHN}$, Clero secular regular, libro 8249, f. 11.
} 
canutillos de oja de lata para las luçes" ${ }^{26}$. 37 reales más se invirtieron en elementos escenográficos, por "una soga grande de cáñamo [...] para el candilon que se pusso en el monumento de nuebas luçes y despues sirvió para las canpanas, y una polea para colgar este candilon"27. Por último, 39 reales fueron gastados en las "belas de tinieblas" ${ }^{28}$. La utilización de la luz a través de velas y otros artilugios, para imbuir al fiel de un estado de ánimo acorde con el misterio de la Pasión, muerte y resurrección de Cristo, se observa en este tipo de manifestaciones a lo largo de toda la Edad Moderna, contando con algunos ejemplos gráficos tardíos como la Vista del Monumento de Semana Santa del Real Monasterio de San Lorenzo, dibujado por José Gómez de Navia y grabado por Manuel Alegre (Fig. 1), donde apreciamos el importante protagonismo de las velas en los monumentos pascuales.

Aparte de los efectos de iluminación buscados con estos aparatos, las citadas noticias nos dan cuenta de la reutilización de los elementos constructivos de los monumentos de Semana Santa, con la compra de una soga que, una vez finalizada la celebración, fue empleada para mover las campanas de la iglesia. El transcurrir del montaje y desmontaje de la estructura se deja sentir en los últimos pagos que se registraron de clavos, tachuelas y "gastos sueltos y menudos que hiço en el dicho monumento de traer y llebar colgaduras y candeleros" 29 . El cómputo final de todos los gastos para levantar y decorar el monumento de 1632 alcanzó los 1865,5 reales, de los cuales, la inversión más alta, con mucha diferencia, fueron los 440 reales pagados a Jusepe Leonardo por las pinturas.

A partir del año 1632, la iglesia de Santa María de la Almudena contaba ya con un monumento de Semana Santa destinado a su reutilización en las sucesivas celebraciones, lo que no impidió los constantes gastos en años posteriores para reparar y mejorar su estructura y decoraciones. Con ocasión de la fiesta de 1633, y en los años siguientes, comienzan a hacer acto de presencia los pagos por armar y desarmar la obra, empleando en estas tareas a los mismos carpinteros que se encargaron de su primera construcción. En 1633 se pagó al carpintero Domingo Rodríguez "catorçe reales del jornal de dos dias que se ocupo en repasar todas las cossas del monumento $=y$ dos reales de la ocupaçion de medio dia en darle de oropel y vidrio, y los restantes por los dias que se ocupo en armar y desarmar el monumento" ${ }^{\prime 30}$. En estas tareas de reparación se tuvieron que emplear cuarenta tablas nuevas, así como "treinta reales [...] en oropel y bidrio bufado para renobar algunas cossas $^{\prime 31}$. Una vez terminadas las reparaciones pertinentes en el armazón de madera, se recurrió de nuevo al ensamblador Juan Bautista, citado en esta ocasión como oficial de hacer retablos, encargado de "haçer y deshaçer el monumento y acomodarle en su lugar" ${ }^{\prime 32}$.

\footnotetext{
${ }^{26}$ AHN, Clero secular regular, libro 8249, f. $11 \mathrm{v}$.

$27 \mathrm{AHN}$, Clero secular regular, libro 8249, ff. $11 \mathrm{v}-12$.

${ }^{28} \mathrm{AHN}$, Clero secular regular, libro 8249, f. $13 \mathrm{v}$.

${ }^{29} \mathrm{AHN}$, Clero secular regular, libro 8249, f. 12.

${ }^{30} \mathrm{AHN}$, Clero secular regular, libro 8249, f. $14 \mathrm{v}$.

${ }^{31} \mathrm{AHN}$, Clero secular regular, libro 8249, ff. $13 \mathrm{v}-14$ (cita en f. 14).

32 AHN, Clero secular regular, libro 8249, f. 14v.
} 


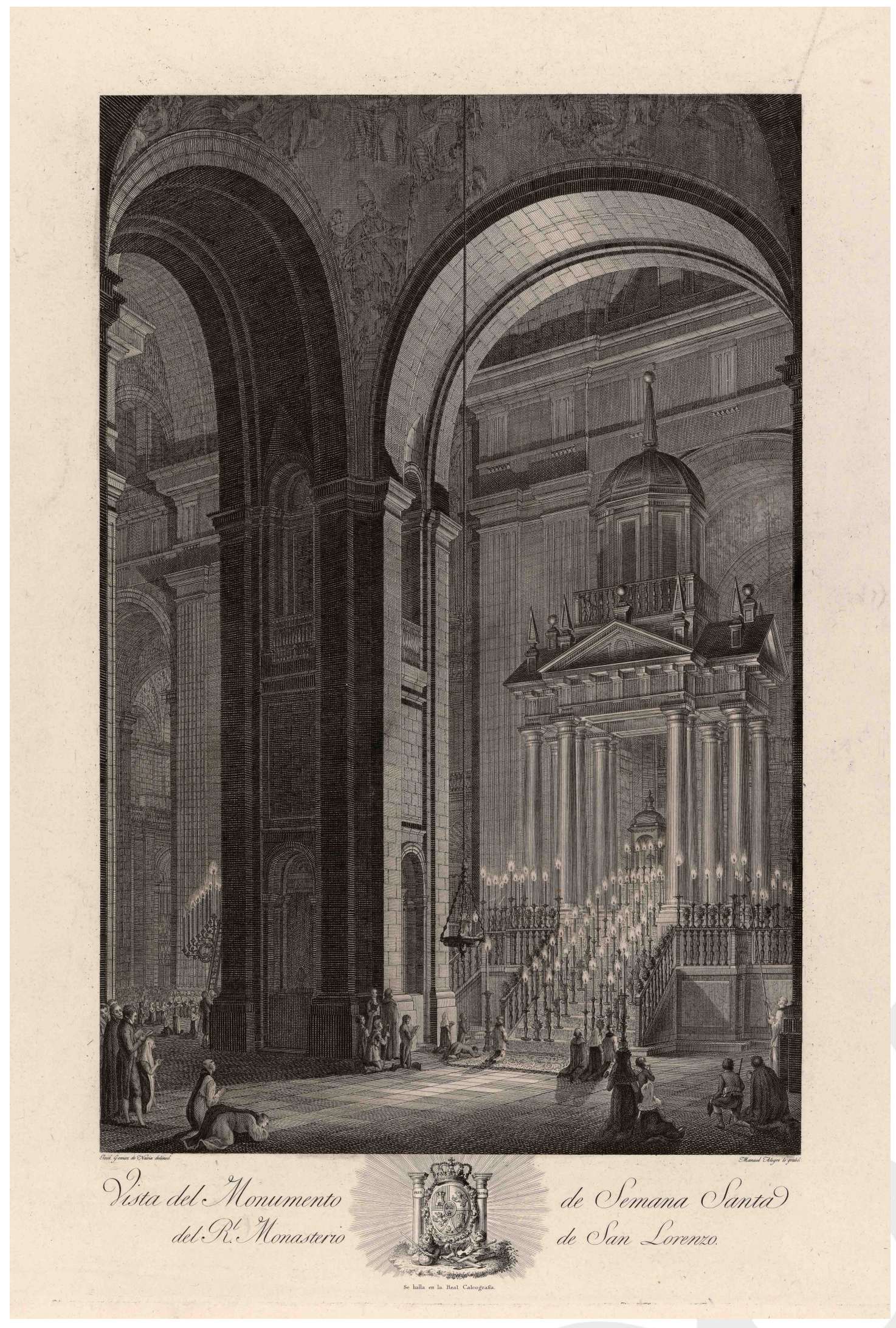

Fig. 1. José Gómez de Navia (dib.) y Manuel Alegre (grab.), Vista del Monumento de Semana Santa del Real Monasterio de San Lorenzo, ca. 1800. Madrid, () Biblioteca Nacional de España (inv. 22924). 
Pero además de las lógicas tareas de reparación y mantenimiento, en el año 1633 se decidió añadir nuevas pinturas, para lo que se acudió una vez más a Jusepe Leonardo. En primer lugar, se gastaron 45,5 reales en 16,5 varas de anjeo para pintar en ellas unas gradillas que debían añadirse a la decoración de la estructura ${ }^{33}$. Posteriormente se libraron al mencionado carpintero Domingo Rodríguez "catorçe reales de dos bastidores para dos pinturas grandes para el monumento"34. A continuación, se hicieron los pagos a Leonardo por la pintura de las nuevas decoraciones, entre las que destacan los lienzos de la Flagelación de Cristo y la Oración en el huerto:

\begin{abstract}
"Yten da por descargo dosçientos y nuebe reales que pagó a Josephe Leonardo pintor, los çinquenta y dos por dibujar $\mathrm{y}$ pintar treçe baras de frisso $=y$ ochenta de pintar quarenta baras para las gradillas = y quarenta y nuebe reales y medio para los colores, y los veinte y siete reales y medio restantes para seis baras de lienço melinje para pintar el açotamiento y oracion del guerto para el monumento $[\ldots]^{\prime 35}$.
\end{abstract}

A través de esta cuenta de gastos se aprecia la completa dedicación del pintor en la decoración de las arquitecturas efímeras de Semana Santa de la iglesia de la Almudena, ya que se encargó personalmente del diseño y acabado de los frisos y gradas, junto con la realización de varias pinturas. La relación de Jusepe Leonardo con la iglesia de Santa María debió de ser muy estrecha si tenemos en cuenta que, en esta ocasión, el artista renunció al pago del jornal y solo recibió las cantidades correspondientes a los colores empleados en las pinturas: "Yten da por descargo cinquenta reales que dio al dicho Josephe Leonardo para los colores de las pinturas que se diçe en la partida de arriba, porque lo demás de su trabajo lo hiço de limosna"36. Esta renuncia a una parte del dinero que le correspondía por las pinturas puede ser indicativa también de una estrategia comercial de Leonardo, puesto que, mediante la aceptación de unas condiciones ventajosas para la fábrica de la iglesia, el artista trataría de asegurarse los encargos de monumentos en años sucesivos.

La suntuosidad que mostraba la iglesia de la Almudena, durante la celebración de la Semana Santa, en la que destacaría su monumento con las arquerías y columnas, junto con las pinturas de Leonardo, se completa con las tapicerías que ornaban el interior del edificio en los días más señalados. En 1633 se pagaron 142 reales "por colgar toda la yglesia de tapiçeria la semana santa de este presente año"37, decoración a la que se sumaban los habituales ramos, en los que se gastaron 8 reales en los años de 1632 y $1633^{38}$.

\footnotetext{
${ }^{33}$ AHN, Clero secular regular, libro 8249, f. 14.

${ }^{34}$ AHN, Clero secular regular, libro 8249, f. $14 \mathrm{v}$.

${ }^{35} \mathrm{AHN}$, Clero secular regular, libro 8249, f. 15.

${ }^{36} \mathrm{AHN}$, Clero secular regular, libro 8249, f. 15.

37 AHN, Clero secular regular, libro 8249, f. 15v.

${ }^{38} \mathrm{AHN}$, Clero secular regular, libro 8249, f. 15v.
} 
En la década de 1630 asistimos a una constante vinculación entre la fábrica de la Almudena y Jusepe Leonardo. Como es bien sabido, el pintor y su mujer, María de Cuellar, establecieron un censo el 11 de noviembre de 1632 a favor de la fábrica de la iglesia de Santa María, sobre la casa que habían adquirido en la calle de las Huertas el 23 de agosto del año anterior y sobre otras tierras y propiedades del matrimonio ${ }^{39}$. A ello se añade el encargo que realizó la fábrica de la iglesia al escultor Manuel Pereira y Jusepe Leonardo de una talla de Cristo, "que están obligados a hacerle de madera y pintura", conocido hasta ahora gracias al documento notarial de la carta de pago fechada en 4 de noviembre de $1633^{40}$. La localización de esta carta de pago evidenció por primera vez que Jusepe Leonardo se había ocupado de policromar estatuas de su estrecho amigo y colaborador Pereira, cuya relación está bien documentada ${ }^{41}$. Gracias a las cuentas del libro de la fábrica de la Almudena, que recogen los detalles del pago a Pereira y Leonardo por "la echura de un santo Cristo que estan haçiendo por mandado del señor Gobernador concertada en dos mil y cien reales" ${ }^{\prime 42}$, podemos añadir algo más acerca de las tareas que ocuparon al pintor dentro de esta obra. Seguidamente se libraron doce reales y medio "a Josephe Leonardo pintor por adereçar la ymagen del Santo Cristo y ponerle unos dedos de cera"43, una tarea, la de la reparación de la mano de Cristo, que amplía el espectro de funciones y habilidades que hasta ahora asignábamos a Leonardo. Coincidiendo con la fecha de la fundación del censo a favor de la fábrica de Santa María, en 1632, y el encargo junto a Manuel Pereira de la talla de Cristo, en 1633, comienzan a registrarse los primeros pagos a Jusepe Leonardo por la decoración del monumento pascual de la Almudena que, como veremos, continuarán a lo largo de toda esta década.

Entre los años 1634 y 1637 se suceden las celebraciones de Semana Santa con el montaje y desmontaje del monumento sin otras actuaciones relevantes, salvo alguna noticia que aporta nuevos datos sobre el proceder en la gestión de estas construcciones estacionales. En primer lugar, destaca

\footnotetext{
${ }^{39}$ Archivo Histórico de Protocolos de Madrid (AHPM), la compra de la casa en prot. 6116, ff. 600-607 y la fundación del censo en prot. 5943, ff. 770-775v. Recogido en María Ángeles Mazón de la Torre, Jusepe Leonardo y su tiempo, (Zaragoza: Institución Fernando el Católico, 1977), pp. 382-386, doc. 38, y 386390, doc. 39; Ramón Torner Marco, Jusepe Leonardo. Un pintor bilbilitano en la Corte de Felipe IV, (Zaragoza: Institución Fernando el Católico, 2007), pp. 33-34.

40 AHPM, prot. 2590, ff. 324-324v. Recogido en María Ángeles Mazón de la Torre, "En torno a Jusepe Leonardo", Archivo español de arte, 48, 190-191, (1975), pp. 269-270; Mazón de la Torre, Jusepe Leonardo, pp. 390-391, doc. 40; Torner Marco, Jusepe Leonardo, pp. 37-38, 97 y 123.

${ }^{41}$ Véase María del Carmen Martín Montero, "Jusepe Leonardo y Manuel Pereira", Archivo español de arte, 25, 98, (1952), p. 170; Mazón de la Torre, Jusepe Leonardo, pp. 290-292; Mercedes Agulló Cobo, "Manuel Pereira: aportación documental", Boletín del Seminario de Estudios de Arte y Arqueología, 44, (1978), p. 278, doc. 69.

${ }_{42}$ AHN, Clero secular regular, libro 8249, f. 26. En este folio, las cuentas de la fábrica de Santa María recogen la libranza de los primeros 1000 reales pagados al pintor y al escultor por la talla de Cristo: "Yten da por descargo mil reales que ha pagado a Josephe Leonardo pintor y Manuel Pereira escultor, vezinos de esta villa, a quenta de la echura de un Santo Cristo que estan haçiendo por mandado del señor Gobernador concertada en dos mil y çien reales a toda costa, y los quinientos dio de limosna un deboto de manera que no se les deven mas de seisçientos reales de que mostró carta de pago ante Juan de Montoya scrivano". En el folio $62 \mathrm{v}$ se refiere la finalización del pago de la escultura a los dos artistas: "Yten da por descargo seisçientos reales que pareçe pagó a Manuel Pereira y Josephe Leonardo escultor y pintor con los quales se les acabó de pagar los dos mil y çien reales en que se conçertó la hechura del Santo Cristo, de que mostró carta de pago otorgada en onçe de mayo de seisçientos y treinta y quatro ante Diego de Ledesma scrivano del numero de esta villa".

43 AHN, Clero secular regular, libro 8249 , f. $26 \mathrm{v}$.
} 
el hecho de que se optara por el alquiler de elementos decorativos para enriquecer el aspecto de la iglesia cuando no era posible encargarlos nuevos. Sucedió así en la Semana Santa de 1634, cuando se pagaron 558 reales a Gregorio Ruiz, encargado en estos años de armar y desarmar la estructura, incluyendo en el precio "el alquiler de unos reposteros y damascos"44. En 1635 se gastaron 63 reales "en colgaduras con lo que se dio a los reposteros del Conde de Castrillo porque las descolgasen y colgarlas en las naves"45. En segundo lugar, para las reparaciones menores de pintura, cuando el monumento en su conjunto se encontraba en buen estado, parece que se recurría a pintores de menor nombradía, acudiendo a Jusepe Leonardo solo cuando eran necesarias nuevas pinturas y actuaciones de cierta envergadura. Es el caso del año 1636, cuando se pagaron 73 reales "a un pintor que pintó unas gradillas y corredorçillos", sin especificar el nombre el artista ${ }^{46}$.

En los años 1638 y 1639 encontramos nuevos encargos de pintura a Jusepe Leonardo. En la Semana Santa de 1638 se decidió realizar algunos cambios en el acabado de los motivos decorativos, optando por el jaspeado para las gradas y demás elementos arquitectónicos, por lo que se pagaron 450 reales al pintor:

"Yten dio por descargo quatroçientos y çinquenta reales por tantos que pagó a Joseph Leonardo pintor por la ocupaçion y trabajo que hubo en pintar todo el monumento del dicho año de mil y seisçientos y treinta y ocho de jaspeado y cantidad de varas de las gradillas por averle diferençiado a los demás años $[\ldots]^{\prime \prime 4}$.

Al año siguiente de 1639, Jusepe Leonardo recibiría el encargo de pintar de nuevo las columnas y gradas del monumento, que seguramente se habían deteriorado con las constantes manipulaciones y los largos periodos de tiempo que pasaba desmontado y almacenado. En esta ocasión, la cuenta de los gastos nos da noticia también de otro trabajo de policromado de estatuas por parte del pintor, con lo que se consolida esta faceta dentro de su producción artística, que en ningún caso debió de ser anecdótica. Al parecer, durante las tareas de preparación y colocación del nuevo retablo principal de Santa María, se localizó una talla de la Virgen detrás del altar mayor, que pasó a formar parte, tras los arreglos de Leonardo, de la decoración permanente de la iglesia:

"Yten dio por descargo y se le pasan en quenta duçientos y ocho reales por tantos que pagó a Joseph Leonardo pintor por los colores y ocupaçion que hubo en dar de colores las colunas y gradas del monumento, y assi mismo en

\footnotetext{
${ }^{44}$ AHN, Clero secular regular, libro 8249, f. $42 \mathrm{v}$.

${ }^{45} \mathrm{AHN}$, Clero secular regular, libro 8249, f. 54.

${ }^{46} \mathrm{AHN}$, Clero secular regular, libro 8249, f. 43v. Encontramos otros pequeños pagos a pintores y doradores como Nicolás Martín o Martín de Velasco en ff. 25 y 85 respectivamente.

47 AHN, Clero secular regular, libro 8249, f. 85v.
} 
luçir la ymagen de Nuestra Señora que se halló detras del altar mayor y se passó a los pies de la yglessia $[\ldots]^{\prime \prime 4}$.

A partir de esta fecha desaparecen los pagos a Jusepe Leonardo, por lo que entendemos que su tarea en la decoración del monumento de la iglesia puede circunscribirse a los años 1632-1639. Con posterioridad a esta fecha se alternarán épocas de reutilización del aparato preexistente y otras en las que se hará necesaria su renovación o incluso su reconstrucción total. En la primera mitad de la década de 1640 la obra de Leonardo se encontraría aún en buen estado de conservación, por lo que únicamente se hacen pequeños pagos a pintores menores o aprendices para el mantenimiento de las partes más gastadas. En el año 1642 se pagaron tres reales "a un moço pintor que renobó de colores unas pilastras del monumento que estavan maltratadas" 49 . Contrastan estos pequeños gastos encaminados a las reparaciones de zonas dañadas, con la importante inversión realizada con Jusepe Leonardo en años anteriores para abordar el diseño y pintado de decoraciones nuevas.

Ya en 1646 se hizo necesario el encargo de otras pinturas, contratando con el pintor Francisco de Morales ${ }^{50}$ ocho nuevos lienzos, de los que no se especificaron los temas, por valor de 148 reales ${ }^{51}$. Por otra parte, al carpintero Domingo Rodríguez se le libraron 184 reales por reparar la estructura del armazón de madera y poner bastidores para las pinturas que se estaban haciendo. A estas obras se añadieron los habituales gastos de lienzo y anjeo para pintar en ellos columnas y pedestales:

"- Los çiento y quarenta y ocho reales a Francisco de Morales pintor por ocho lienços que pintó para el dicho monumento [...] / - Los çiento y ochenta y quatro reales que pagó a Domingo Rodríguez carpintero del travajo de aderezar el monumento y añadir algunos bastidores para pintura [...] / - Los çinquenta y dos reales y medio de quinçe baras de lienço para unos vastidores para pintar a tres reales y medio / De diez baras y media de anjeo para clavar

\footnotetext{
${ }^{48} \mathrm{AHN}$, Clero secular regular, libro 8249, f. 86v. Con respecto a los trabajos que se llevaban a cabo en estos años, la fábrica de Santa María pagó 60 reales a Pedro de la Torre por desarmar y quitar los retablos del altar mayor (f. 96v). Las cuentas de la iglesia recogen también el pago de 75 reales a Juan Bautista de San Agustín por el altar que construyó para trasladar la imagen de la Almudena hasta el monasterio de las Descalzas Reales, y otro para acompañar su vuelta a la iglesia de Santa María (f. 96). Por último, la documentación registra algunos de los gastos de la gran fiesta que se organizó cuando la imagen de la Almudena regresó de su estancia en las Descalzas Reales: 200 reales a Gregorio Ruiz por los cohetes y fuegos artificiales, 50 reales a los encargados de tocar las trompetas y 90 reales al ministril y bajón de la Capilla Real Francisco Marcos Castellanos, por la música interpretada aquel día (f. 98).

${ }^{49} \mathrm{AHN}$, Clero secular regular, libro 8249, f. 127.

50 Aún estamos lejos de tener un conocimiento suficiente sobre la personalidad de este artista. Algunas noticias relativas a Francisco de Morales, pintor, documentado en Madrid entre 1627 y 1660 , han sido publicadas por Mercedes Agulló Cobo, Más noticias sobre pintores madrileños de los siglos XVI al XVII, (Madrid: Ayuntamiento de Madrid, 1981), pp. 54, 63-65 y 103; Mercedes Agulló Cobo, Documentos para la historia de la pintura española, (Madrid: Fundación de Apoyo a la Historia del Arte Hispánico, 2006), vol. 3, p. 18; María Ángeles Vizcaíno Villanueva, El pintor en la sociedad madrileña durante el reinado de Felipe IV, (Madrid: Fundación Universitaria Española, 2005), pp. 26, 28, 31-32, 43-44, nota 94, 53, 215, 451 y 463 . A ello podemos añadir su aparición como tasador de las pinturas que quedaron por la muerte de Catalina Arguijo, mujer de Domingo Herrero, cirujano, residentes en Madrid, el 5 de febrero de 1644 (AHPM, prot. 6450, ff. 250-251v).

${ }^{51}$ Recogido en Tarrero Alcón, Santa María, p. 67.
} 
en unos bastidores que se hiçieron y pintaron unos pedestales y colunas quarenta reales $[\ldots]^{\prime \prime 52}$.

El gasto total de la construcción del monumento de 1646, en el que parece que asistimos a una reparación de gran envergadura, pero reutilizando partes anteriores, ascendió a 1885 reales. Este gasto es similar al de otros años, pero significativamente inferior a la inversión en monumentos que se levantarán completamente de nueva planta en fechas posteriores, como veremos más adelante.

La década de 1640 acaba sin mayores inversiones que las habituales del montaje y desmontaje del monumento, el alquiler de candeleros y colgaduras para ornar la iglesia, la compra de incienso, ramos y los gastos en la impresión de "los papeles de los sermones de Nuestra Señora y el Santo Cristo con sus estanpas"53. Los trabajos de montaje se encargan en esta época al carpintero Pedro Romero ${ }^{54}$. El proceso de armar la estructura cada año, y el deterioro al que estaban sometidos los materiales y las decoraciones, se refleja bien en alguno de los pagos, como los 22 reales por mover "las colgaduras y demas alajas con que se adorna el monumento y adereçar algunas que se maltratan"55. Ya en el año 1650, las cuentas dejan constancia de los ingenios y nuevos aires decorativos que van añadiéndose desde mediados del siglo XVII, con la creación de un monte provisto de distintos motivos ornamentales e iluminaciones: "- Mil y çinquenta reales costó el monumento del año de çinquenta, candeleros, blandones, garanchos y caracolas para poner luçes en un monte que se hiço y peñasco, y colgar y todo lo necesario para dicho monumento" ${ }^{156}$.

Para encontrar nuevos pagos de pintura debemos esperar hasta el año 1652. En esta fecha la práctica totalidad del aparato decorativo de la iglesia debía estar ya en muy mal estado, lo que llevó a su fábrica a invertir en nuevas pinturas, cuyas cuentas nos aportan información relevante sobre el proceder en estos casos. Las pinturas se concertaron, como sucedía en muchas ocasiones, con el maestro encargado de la obra de madera, en este caso el ensamblador milanés Juan Bautista de San Agustín, pagando por ellas la nada desdeñable cantidad de 700 reales de vellón, y justificando el gasto por el dispendio que suponía el alquiler de las decoraciones en años anteriores:

"Monumento nuevo / Mas dio por descargo seteçientos reales de vellon que pareçio aver pagado por las pinturas nuevas, pilastras y demas ornato que se compró para el monumento y ornato del, por quanto no lo tenía la yglesia y

\footnotetext{
52 AHN, Clero secular regular, libro 8249, ff. 262-262v.

53 AHN, Clero secular regular, libro 8249, f. 299.

${ }^{54}$ AHN, Clero secular regular, libro 8249, f. 276.

55 AHN, Clero secular regular, libro 8249, f. 299.

${ }^{56} \mathrm{AHN}$, Clero secular regular, libro 8249, f. 300v.
} 
costava cada un año de alquiler mucha cantidad y se conçerto con Juan Baptista de San Agustin -"

Avanzando en la década de 1650 se suceden los habituales procesos de elevación del monumento, encargándose de ello los carpinteros Juan Navarro y Juan Asensio en los años 1655, 1656 y $1657^{58}$. Entre 1661 y 1663 se hacen algunos gastos en retocar la "pintura y demás aderentes que puso Francisco Nicolás maestro arquitecto"59. En los años siguientes de 1668 y 1669 se encargó de armar y desarmar el monumento muy probablemente la misma persona, que en este caso aparece citada con el nombre invertido, Nicolás Francisco, identificado como maestro altarero ${ }^{60}$. Entre los gastos de 1669 destaca el pago de "cinquenta y dos reales de vellon [...] a Diego Calçada por un adereço que hizo en la tramoya del tabernaculo del altar maior"61, buena muestra de la importancia que tenían los ingenios de cuerdas y poleas para mover cortinas que pudiesen cubrir y descubrir los altares y la Sagrada Forma, tanto en las celebraciones de la Semana Santa como durante los oficios religiosos habituales.

Desde 1652 se había estado empleando el monumento encargado a Juan Bautista de San Agustín, -sucesor de las estructuras decoradas por Jusepe Leonardo en la década de 1630-, y que con numerosos arreglos y remiendos debió sobrevivir hasta el año 1674, cuando se decide la construcción de uno nuevo. Esta pauta temporal que nos da la documentación apuntaría a establecer un periodo de utilización de cada monumento, -o al menos de una parte de su estructura-, en torno a los veinte años, desde que se construye uno, hasta que los deterioros son tan notables que se requiere otro totalmente nuevo. No obstante, los constantes pagos a carpinteros, ensambladores y pintores, para arreglar y añadir partes a la estructura original, -así como la constatación de que se alquilaban elementos decorativos en numerosas ocasiones-, nos hablan de construcciones que habían de ser reparadas y alteradas prácticamente desde el segundo año de utilización y durante todas las celebraciones sucesivas.

Así, en virtud de un decreto de 11 de febrero de 1674, el visitador Gabriel de Arenas otorgó licencia al mayordomo de la iglesia, el día 13 de febrero del mismo año, para la construcción de un nuevo monumento en la Almudena. El proyecto de esta nueva construcción festiva supuso el empleo de 4445 reales de vellón, dedicados a "hacer un monumento para la Semana Santa en dicha iglesia por ser muy viejo el que havia y estar podrida la madera y a riesgo de hundirse" ${ }^{\prime 62}$. En esta ocasión se adquirieron 152 varas de lienzo para cubrir la estructura de madera, un armazón cuya construcción corrió a cuenta

${ }^{57}$ AHN, Clero secular regular, libro 8249, ff. 315-315v. Recogido en Tarrero Alcón, Santa María, pp. 6768.

${ }_{58}$ AHN, Clero secular regular, libro 8249, f. 335.

${ }^{59} \mathrm{AHN}$, Clero secular regular, libro 8249, f. 386.

${ }^{60} \mathrm{AHN}$, Clero secular regular, libro 8249 , f. $468 \mathrm{v}$.

${ }^{61} \mathrm{AHN}$, Clero secular regular, libro 8249, f. 514.

${ }^{62}$ AHN, Clero secular regular, libro 8249, ff. 604-604v (cita en f. 604). Recogido en Tarrero Alcón, Santa María, p. 68. 
de Nicolás Francisco, maestro altarero y carpintero, que años atrás se ocupaba del montaje y desmontaje del monumento viejo. Fueron necesarias tres vigas de a tercia de veintidós pies de largo para hacer bastidores; treinta y dos tablas de a nueve para realizar los arcos, perspectivas y treinta y seis gradillas; además de catorce tablas para los remates del monumento. Posteriormente se pagaron 2000 reales a Antonio Buchado por la pintura de toda la estructura, que incluía 18 lienzos con la representación de cuatro profetas y 36 gradas pintadas:

"A Antonio Buchado dos mil reales de vellon que importó la pintura de diez y ocho lienzos de pintura de doblada marca con cuatro profetas y treinta y seis gradas de pintura con sus vastidores de que dio recivo en veinte de abril de setenta y quatro"63.

Entre 1677 y 1680 se gastaron 2999 reales en los sucesivos montajes y desmontajes del monumento de Semana Santa. En este periodo se encargó de las tareas de armar y desarmar la estructura el maestro altarero Juan López, y la capilla dedicada a la construcción del altar se ornó con colgaduras de la casa del conde de Peñaranda64. En este momento empiezan a contabilizarse los gastos junto con los de la fiesta del Corpus Christi y otras festividades que hasta ahora habían recibido un tratamiento diferenciado, dentro de un proceso de unificación de las cuentas que se hará más notorio en la documentación del siglo XVIII. A lo largo de este siglo se mantienen los tradicionales monumentos de Semana Santa, pero los pagos nos ofrecen un menor detalle, con muy escasas menciones a encargos de pinturas, especialmente en comparación con la rica información proporcionada por las cuentas de la centuria anterior.

Algo más de detalle encontramos en las cuentas de los años 1733-1735, en los que la fábrica de la Almudena invirtió la suma de 1108 reales en la construcción del monumento, junto con la decoración de los altares de los Misereres y el Corpus Christi, todo lo cual quedó a cargo del maestro Diego Rodríguez. De ese total, se destinaron 240 reales "a dicho Diego Rodriguez por diferentes aderezos y composturas que hizo de quadros, piezas en los colaterales, bastidores y otras cosas $[\ldots]^{\prime \prime 65}$.

En los años de 1736 y 1737 se pagan 584 reales al mismo maestro por hacerse cargo de las decoraciones efímeras de la iglesia en su conjunto: 480 reales "por el travajo de armar y desarmar el monumento, cubrir los altares y adornar el del Santo Christo de la Salud para los Misereres en las dos quaresmas $[\ldots]$ "; otros 72 reales "por el travajo de armar y adornar los altares para la octava del Corpus [...]"; y los 32 reales restantes "por una gradilla que hizo para el altar maior $[\ldots]^{\prime \prime 66}$. Asistimos así a la pérdida del protagonismo que tenía en las cuentas del siglo XVII la creación y decoración

\footnotetext{
${ }^{63}$ AHN, Clero secular regular, libro 8249, f. 604v. Citado en Tarrero Alcón, Santa María, p. 68.

${ }^{64}$ AHN, Clero secular regular, libro 8247, ff. 17-17v.

${ }^{65} \mathrm{AHN}$, Clero secular regular, libro 8247, sin foliar: cuentas de 1733-1735, data no 10.

${ }^{66} \mathrm{AHN}$, Clero secular regular, libro 8247, sin foliar: cuentas de 1736-1737, data no 10.
} 
del monumento de Semana Santa, que se registraba con todos los pormenores y de forma diferenciada a la del resto de celebraciones religiosas. Además, el presupuesto empleado para el monumento va reduciéndose progresivamente desde finales del siglo XVII y en las primeras décadas del siglo XVIII, hasta llegar a los 584 reales gastados conjuntamente en los dos años de 1736 y 1737, que además se compartían con el resto de gastos propios de las demás celebraciones del calendario litúrgico.

Sobre la tipología del monumento de Semana Santa que se levantaba todos los años en la iglesia de Santa María, las cuentas de la fábrica de la Almudena dan pocas pistas para determinar su forma general. En los pagos que hemos visto, desde 1632 hasta 1737, queda claro que se componía de pilastras sobre las que se apoyaban arcos y gradas, con algunos espacios con lienzos con temas de la Pasión. La compra de cinco varas de anjeo para la media naranja del remate del monumento, en 1637, añade otro dato relevante sobre el diseño de la estructura en fechas muy tempranas ${ }^{67}$. El resto de pagos realizados a los artistas no aporta más información, pero contamos con una sucinta descripción del monumento que se conservaba en la Almudena a través del inventario de bienes de la iglesia redactado en 1710 . En la sección del inventario dedicada a las pinturas y esculturas encontramos "Un monumento que se compone de cuatro cuerpos con sus medios puntos y pilastras y un pozo todo pintado"68. En varios de sus lados, el espacio entre las pilastras estaría cubierto por lienzos decorados con escenas alusivas a la Pasión como los que refieren los pagos documentados. Como era habitual en todos los monumentos de Semana Santa, el centro de la estructura contenía el sagrario con la reserva de la eucaristía, que adoptaba la forma de cofre, arca o tabernáculo y que podía ubicarse en un altar o dentro de un nicho en clara alusión al sepulcro de Cristo, como parece que sucedía en el monumento de la Almudena de 1710 según la descripción del inventario ${ }^{69}$. En el caso de la iglesia de Santa María, Tarrero Alcón ha documentado la tipología del arca de plata realizado para la reserva del Santísimo en el monumento pascual: tenía forma cuadrada con molduras de ébano de Portugal y decoración cincelada con representaciones de bichas en las esquinas a modo de pies, además de mascarones a los lados decorando las asas. En su tapa contaba con figuras de medio relieve alusivas a la Resurrección: un cordero portando el estandarte del triunfo y una imagen de Cristo, todo ello en plata ${ }^{70}$.

\section{Jusepe Leonardo en la década de 1630: un artista al servicio de la corona y el arzobispado de Toledo}

Varias circunstancias conocidas de la biografía de Jusepe Leonardo conectan al artista tanto con la corte como con las altas jerarquías de la

\footnotetext{
${ }^{67}$ AHN, Clero secular regular, libro 8247, f. 88v.

68 El texto del inventario en Tarrero Alcón, Santa María, Apéndice: Inventario de 1710, n० 27

${ }^{69}$ Sobre las distintas tipologías de monumentos y el lugar que ocupaba en ellos el sagrario, véase Calvo Ruata y Lozano López, "Los monumentos de Semana Santa en Aragón", pp. 103-108, especialmente p. 104.

70 Tarrero Alcón, Santa María, pp. 68-69.
} 
iglesia. Por una parte, Leonardo aparece vinculado desde mediados de la década de 1630 con las obras reales, encargado de la decoración del Salón de Reinos del Palacio del Buen Retiro, participando con dos grandes escenas de batallas, la Rendición de Juliers (Museo Nacional del Prado, P-858) y el Socorro de Brisach (Museo Nacional del Prado, P-859). Estas pinturas, junto con el resto de los cuadros de acontecimientos bélicos realizados por Maíno, Velázquez, Carducho, Zurbarán, Pereda, Cajés y Castelo, fueron contratadas en 1634 y estaban terminadas para el mes de abril de $1635^{71}$. Poco después debió de encargarse la serie dinástica de los retratos de Reyes Godos, destinados también muy probablemente al Palacio del Buen Retiro. En esta ocasión se contó de nuevo, entre la nómina de artistas seleccionados, con la presencia de Jusepe Leonardo, que hizo el retrato de Alarico (Museo Nacional del Prado, P-3391) ${ }^{72}$. La conformidad con el resultado de las pinturas de Leonardo tuvo que ser muy alta, si tenemos en cuenta que el artista continúo interviniendo en los proyectos decorativos de los años siguientes en la corte, junto a los principales pintores de su tiempo. Es el caso de la serie de retratos de los reyes de Asturias, León y Castilla, para la decoración del Salón Dorado del Alcázar, encargada a finales de 1639, en la que Jusepe Leonardo intervino pintando, según la propuesta generalmente aceptada, los retratos dobles sedentes de Berenguela y Fernando III, Alfonso X y Sancho IV, Fernando IV y Alfonso $X I$, y Pedro $I$ y Enrique $I I^{73}$. En los mismos años, Jusepe Leonardo realizó cuadros con vistas de sitios reales y se dedicó también a la pintura mural. Con respecto a la pintura de sitios reales se le han atribuido con algunas dudas, desde las aportaciones de María Luisa Caturla en 1947 hasta nuestros días, dos vistas del Palacio del Buen Retiro, otra del Palacio de Aceca y varias vistas de casas de campo propiedad de la corona, fechables todas hacia $1637^{74}$. Más interesante es la constatación documental de que Leonardo trabajó en varios proyectos de decoraciones murales, lo que nos da idea, junto con su dedicación a la pintura de arquitecturas efímeras en la Almudena, de la amplitud de sus conocimientos técnicos y la variedad de modalidades artísticas que practicó, más allá de la pintura de caballete. Sabemos por dos documentos notariales, publicados por el marqués del Saltillo, que Leonardo se comprometía en 1635 a pintar la pieza baja de la ermita de San Jerónimo, en los jardines del Buen Retiro, aunque documentos

\footnotetext{
${ }^{71}$ María Luisa Caturla, "Cartas de pago de los doce cuadros de batallas para el Salón de Reinos del Buen Retiro", Archivo español de arte, 33, 132, (1960), pp. 333-356; Mazón de la Torre, Jusepe Leonardo, pp. 138-166 y 359; Torner Marco, Jusepe Leonardo, pp. 35, 56-62, 100, 119 y 124.

72 Sobre esta pintura véase Mazón de la Torre, Jusepe Leonardo, pp. 175-180 y 359; Torner Marco, Jusepe Leonardo, pp. 85 y 120.

73 Ángel Aterido Fernández, "Alonso Cano y la alcoba de su majestad: la serie regia del Alcázar de Madrid", Boletín del Museo del Prado, 20, 38, (2002), pp. 9-36. Sobre esta serie véase también María Luisa Caturla, "Los retratos de Reyes del Salón Dorado en el antiguo Alcázar de Madrid", Archivo español de arte, 20, 77, (1947), pp. 1-10; Mazón de la Torre, Jusepe Leonardo, pp. 181-192 y 359; Torner Marco, Jusepe Leonardo, pp. $85-86$ y $120-121$.

${ }^{74}$ María Luisa Caturla, Pinturas, frondas y fuentes del Buen Retiro, (Madrid: Revista de Occidente, 1947), pp. 35-38, en especial p. 38. Sobre las vistas de sitios reales atribuidas a Leonardo véase también Mazón de la Torre, Jusepe Leonardo, pp. 283-287 y 360; Torner Marco, Jusepe Leonardo, pp. 89-93 y 122 . Acerca de la dificultad de atribución de estas pinturas, un estado de la cuestión en Álvaro Pascual Chenel y Ángel Rodríguez Rebollo, "¿A la sombra de Velázquez? Los pintores cortesanos durante el reinado de Felipe IV", en La corte de Felipe IV (1621-1665). Reconfiguración de la Monarquía católica, coords. José Martínez Millán y Manuel Rivero Rodríguez, (Madrid: Polifemo, 2017), t. 3, vol. 4, pp. 2709-2710, nota 93.
} 
posteriores demuestran que el proyecto finalmente no llegó a realizarse. Sí que debieron de concluirse las pinturas murales de la Capilla Real del Alcázar, en la que tal y como cuenta Pedro de Madrazo en su catálogo del Museo del Prado en 1872, Félix Castelo pintó la bóveda de la primera pieza y Leonardo la de la segunda, a partir de 1641, según documentos vistos por el historiador en el Archivo de Palacio. Estas obras de Leonardo, a las que se suman las pinturas del relicario situado bajo la Capilla Real, terminadas por Angelo Nardi, se perdieron en el incendio de $1734^{75}$.

Por otra parte, además de la constante presencia en los proyectos artísticos de la corte, el nombre de Jusepe Leonardo aparece mencionado en la documentación entre los pintores que estaban al servicio del arzobispado de Toledo durante las primeras décadas del siglo XVII. El documento que recoge la noticia consiste en una relación de los bordadores, plateros, pintores, escultores y otros artistas y profesionales que se encontraban al servicio del consejo de la gobernación del arzobispado de Toledo desde el año 1602 en adelante. En la citada relación figura "Jusepe Leonardo pintor de Madrid", una escueta mención que deja constancia de la participación del artista en la decoración de algunas de las iglesias y conventos que conformaban la extensísima diócesis toledana, a la que evidentemente pertenecían también las fundaciones religiosas de la villa de Madrid. Un segundo documento, que registra los encargos que se hacían a los artistas del arzobispado toledano en los mismos años, contiene una interesante información sobre el papel de Leonardo en la obra del retablo principal de la iglesia de Torrejón de Ardoz. De la estructura de madera se hizo cargo su buen amigo, el maestro ensamblador y escultor Juan Bautista Garrido76, a partir del 30 de agosto de 1636, mientras que Jusepe Leonardo, "pintor de su magestad", recibió el 20 de septiembre del mismo año el encargo de la pintura, dorado y estofado del retablo, hoy perdido ${ }^{77}$. Otros ejemplos de

\footnotetext{
75 Sobre Leonardo y el proyecto de decoración mural de la ermita de San Jerónimo en el Buen Retiro, véase Marqués del Saltillo, "Artistas madrileños (1592-1850)", Boletín de la Sociedad Española de Excursiones, 57, (1953), pp. 176-178; Mazón de la Torre, Jusepe Leonardo, pp. 288-290; Torner Marco, Jusepe Leonardo, pp. 94-96 y 123. Sobre su participación en las decoraciones murales del Real Alcázar Pedro de Madrazo, Catálogo descriptivo e histórico del Museo del Prado de Madrid, (Madrid: Imprenta y estereotipia de M. Rivadeneyra, 1872), p. 427; Mazón de la Torre, Jusepe Leonardo, pp. 287-288; Torner Marco, Jusepe Leonardo, pp. 96 y 122-123.

${ }^{76}$ Sobre Juan Bautista Garrido véase principalmente Mercedes Agulló Cobo, Documentos sobre escultores, entalladores y ensambladores de los siglos XVI al XVIII, (Valladolid: Universidad de Valladolid, 1978), pp. 71-74; Agulló Cobo, Manuel Pereira: aportación documental, pp. 258, 260 y docs. 8, 9, 10, 27 y 69; María Ángeles Mazón de la Torre, "Escultores madrileños del siglo XVII: Juan Bautista Garrido", en Miscelánea de arte, (Madrid: Consejo Superior de Investigaciones Científicas, Instituto Diego Velázquez, 1982), pp. 137-139.

77 Archivo Diocesano de Toledo (ADT), Libros, no 3044, Libro donde se escriben los nombres de los oficiales de este Arçobispado a los quales se dan las obras de las yglesias del por su señoria illustrisima y señores de su Consejo y començo a 27 de otubre de 1602, f. 328. ADT, Libros, no 3043, Libro de las obras de este arçobispado desde el año de mil y seiscientos y treze y algunas desde doce que se an encargado en el Consejo del Cardenal mi señor. Libranzas y notarios, f. 166v. Una transcripción completa de ambos documentos en Manuel Gutiérrez García-Brazales, Artistas y artífices barrocos en el Arzobispado de Toledo, (Toledo: Obra Cultural de la Caja de Ahorro Provincial de Toledo, 1982), pp. 49, 197 y 336. El primero de los documentos citados fue dado a conocer por Verardo García Rey, "Artistas madrileños al servicio del Arzobispado de Toledo", Revista de la biblioteca, archivo y museo, 29, (1931), pp. 76-87. En este artículo, García Rey presenta de forma conjunta a Jusepe Leonardo y otro artista, Alejo de Calzada, pintor y dorador de Madrid, en 5 de febrero de 1635 (p. 83). Lo cierto es que, en el manuscrito original, sus nombres únicamente aparecen seguidos en la secuencia de los oficiales que conforman el índice (f. $3 \mathrm{v})$, sin que sus trabajos y encargos tengan después relación alguna en el resto del documento.
} 
trabajos de Jusepe Leonardo dentro de la demarcación territorial del arzobispado toledano son más conocidos, como su pintura de la Anunciación en la iglesia de Santa María de Casarrubios del Monte (Toledo), firmada por el artista; las pinturas del retablo mayor de la iglesia parroquial, hoy catedral, de Santa María Magdalena de Getafe (Madrid), contratadas por Jusepe Leonardo, Félix Castelo y Angelo Nardi en mayo de 163978; así como las pinturas del retablo de la iglesia de La Torre de Esteban Hambrán (Toledo), cuyo contrato fue firmado por Leonardo también en mayo de 1639, aunque la entrega de algunos de los lienzos aparentemente se demoraría hasta $1641^{79}$.

Dentro de este contexto, con Leonardo plenamente inmerso en los programas decorativos de mayor importancia de la corte, y al servicio del arzobispado toledano, se entiende mejor su continua participación en la pintura de los monumentos de Semana Santa de la iglesia de la Almudena. El primer encargo de la fábrica para pintar el monumento data de 1632, dos años antes de la llamada a palacio para participar en las decoraciones del Salón de Reinos. El mismo año de 1632 Leonardo y su mujer fundaban el mencionado censo a favor de la fábrica de la Almudena. Después vendrán los pagos de 1633 por las pinturas de la Flagelación de Cristo y la Oración en el huerto, -coincidiendo con el conocido encargo de la talla de Cristo junto al escultor Pereira-, así como la decoración completa de los monumentos de 1638 y 1639 . Este último año, el pintor también recibió pagos por policromar la talla de la Virgen localizada tras el altar mayor, que se puso a los pies de la iglesia. Teniendo en cuenta la constante vinculación de Leonardo con la fábrica de Santa María no resulta extraño que, en el momento de contratarse en 1638 el dorado del retablo mayor de la iglesia, se obligara al maestro dorador Pedro Martín de Ledesma a encomendar la pintura del Milagro del pozo a Jusepe Leonardo, Vicente Carducho o Diego Velázquez, como ha documentado Cruz Yábar recientemente ${ }^{80}$. La indicación en primer lugar de Leonardo, por delante de Carducho o Velázquez, se explica por el perfecto conocimiento que la fábrica de Santa María tenía del pintor, que trabajaba en sus monumentos pascuales desde al menos 1632. Ya en los primeros años de la década de 1630 la documentación deja constancia de que Leonardo contaba con un importante taller con varios oficiales, capaz de hacer frente a proyectos de envergadura como la decoración de un monumento de Semana Santa, por lo que no queda claro el motivo por el que Leonardo no llegó a

\footnotetext{
78 Sobre la Anunciación de Casarrubios y la atribución de las pinturas de Getafe, véase Mazón de la Torre, Jusepe Leonardo, pp. 201-202 y 255-266; Torner Marco, Jusepe Leonardo, pp. 35-36, 63-64 y 73-76. Actualmente la firma de la Anunciación de Casarrubios resulta prácticamente ilegible. Por otra parte, esta pintura ha sido objeto de una desacertada restauración que desvirtúa su calidad original, afectando especialmente a las manos y el rostro de los personajes.

79 Fernando Collar de Cáceres, "Jusepe Leonardo en el retablo de La Torre de Esteban Hambrán", Archivo español de arte, 68, 269, (1995), pp. 1-16.

80 Juan María Cruz Yábar, "El milagro del pozo de Alonso Cano para el retablo de Santa María de la Almudena. Documentos inéditos", Boletín del Museo del Prado, 36, 54, (2018), pp. 48-60.
} 
hacerse cargo de una pintura de tanta relevancia como el Milagro del pozo (Museo Nacional del Prado, P-2806), finalmente realizada por Alonso Cano ${ }^{81}$.

En cualquier caso, resulta evidente la cercanía entre la fábrica de la iglesia de la Almudena y los pintores relacionados con la corte en la primera mitad del siglo XVII. Este hecho se constata con los encargos que hemos documentado de Jusepe Leonardo y en la biografía de otros artistas como el propio Alonso Cano o Diego Polo. Este último participó también en la serie de retratos para la alcoba del rey con dos retratos de parejas de reyes, hoy desaparecidos, uno de ellos representando a Ramiro II y Ordoño III. Igualmente, y según nos cuenta Palomino, "en la iglesia de Santa María de Madrid pintó una Anunciata, que está en la cúpula de la capilla mayor, que también es excelente pintura, y todos la tienen por de Carreño"82. Parece lógico que una iglesia que disfrutaba del apoyo creciente de la casa real acudiese para sus principales encargos artísticos a pintores del entorno cortesano: Jusepe Leonardo para el policromado y arreglo de estatuas y los monumentos pascuales; Diego Polo para la Anunciación de su cúpula mayor y, -tras la propuesta inicial de Leonardo, Carducho o Velázquez-, la aceptación de Alonso Cano para la pintura del Milagro del pozo del retablo principal.

Por lo que respecta a las obras de Leonardo en la Almudena, debido a las condiciones adversas de conservación a las que eran sometidas las construcciones efímeras de Semana Santa, montadas y desmontadas todos los años, lo más seguro es que la totalidad de sus pinturas para los monumentos se hayan perdido. No obstante, tras el estudio pormenorizado de los inventarios de bienes de la iglesia de Santa María, cuya trascripción fue realizada por Tarrero Alcón en su mencionada tesis doctoral, podemos plantear la hipótesis de que al menos la Flagelación de Cristo y la Oración en el huerto, -encargadas a Leonardo para el monumento de 1633-, pudieron sobrevivir como una pareja de cuadros exentos, separados en algún momento de la estructura del monumento, hasta finales del siglo XVIII.

Así, en el inventario de los bienes de la iglesia redactado en 1693 se citan "Dos pinturas iguales de la oración en el huerto y la columna muy maltratadas en la capilla a los pies de la iglesia"83. La mención a los temas de los cuadros, una Oración en el huerto y un Cristo atado a la columna, permite relacionarlos con los pintados por Jusepe Leonardo en 1633, mencionados en los pagos como "oracion del guerto" y "açotamiento" respectivamente. Es muy probable que la pintura del azotamiento o flagelación representara la figura de Cristo

\footnotetext{
${ }^{81}$ Cruz Yábar, El milagro del pozo, p. 54 apunta algunas de las causas que pudieron llevar a la elección final de Alonso Cano para pintar el cuadro. Sobre la vida del artista véase también Javier Portús Pérez, "Alonso Cano: la creación de una leyenda", en Veintitrés biografías de pintores, coord. Francisco Calvo Serraller, (Madrid: Mondadori-Fundación Amigos del Museo del Prado, 1992), pp. 319-344.

82 Palomino de Castro y Velasco, El parnaso español, pp. 873-874. Sobre Diego Polo véase principalmente Alfonso Emilio Pérez Sánchez, "Diego Polo", Archivo español de arte, 42, 165, (1969), pp. 43-54; Diego Angulo Íñiguez y Alfonso Emilio Pérez Sánchez, Historia de la pintura española. Escuela madrileña del segundo tercio del siglo XVII, (Madrid: Consejo Superior de Investigaciones Científicas, Instituto Diego Velázquez, 1983), pp. 240-252.

83 Tarrero Alcón, Santa María, Apéndice: Inventario de 1693, no 48.
} 


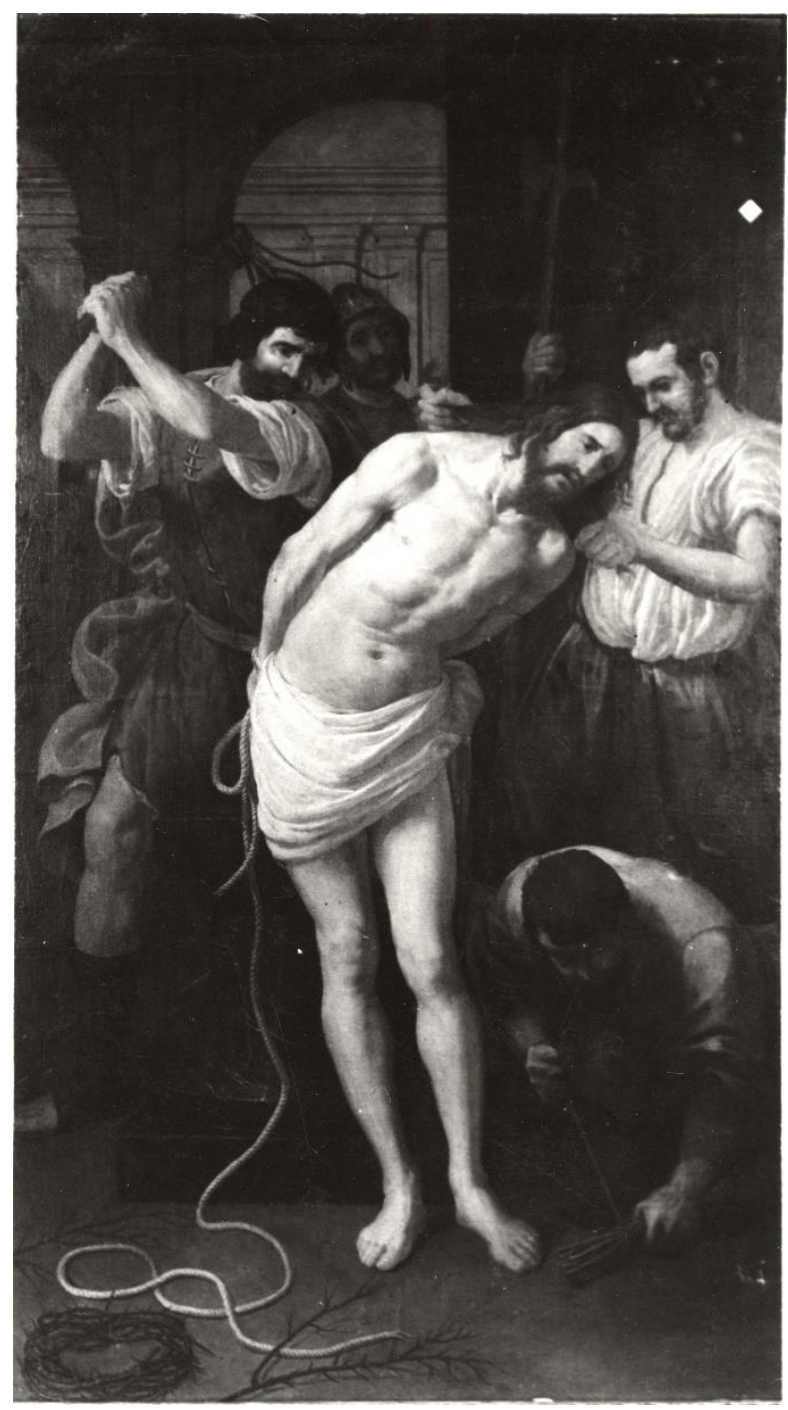

Fig. 2. Atribuido a Jusepe Leonardo, Flagelación de Cristo, ca. 1625-1630, pintura en paradero desconocido. Fotografía: Madrid, (c) CSIC, Archivo del Centro de Ciencias Humanas y Sociales (inv. ATN/DAP/33).

atado a la columna, rodeado por los sayones provistos de los flagelos, una iconografía frecuente en el siglo XVII y que pudo motivar la mención al cuadro de ambas formas, como azotamiento en los primeros pagos y como Cristo atado a la columna en los inventarios de los siglos posteriores. La condición de pareja de los cuadros y el hecho de que estuvieran ya muy deteriorados en 1693 sugiere igualmente que podrían ser los lienzos que realizó Leonardo para el monumento de Semana Santa sesenta años atrás. Como afirma Tarrero Alcón, estos cuadros desaparecen del inventario de 1710, quizás por haber sido retirados temporalmente del templo para ser limpiados o restaurados ${ }^{84}$, lo que explicaría su reaparición en inventarios posteriores. En 1777, con motivo de las obras de reparación llevadas a cabo en la iglesia, se trasladó el culto y los bienes de la Almudena al convento de las Madres Bernardas del Santísimo Sacramento, lo que motivó la redacción de un nuevo inventario en el que encontramos "Otra pintura de Nuestro Señor atado a la

84 Tarrero Alcón, Santa María, pp. 114-115. 


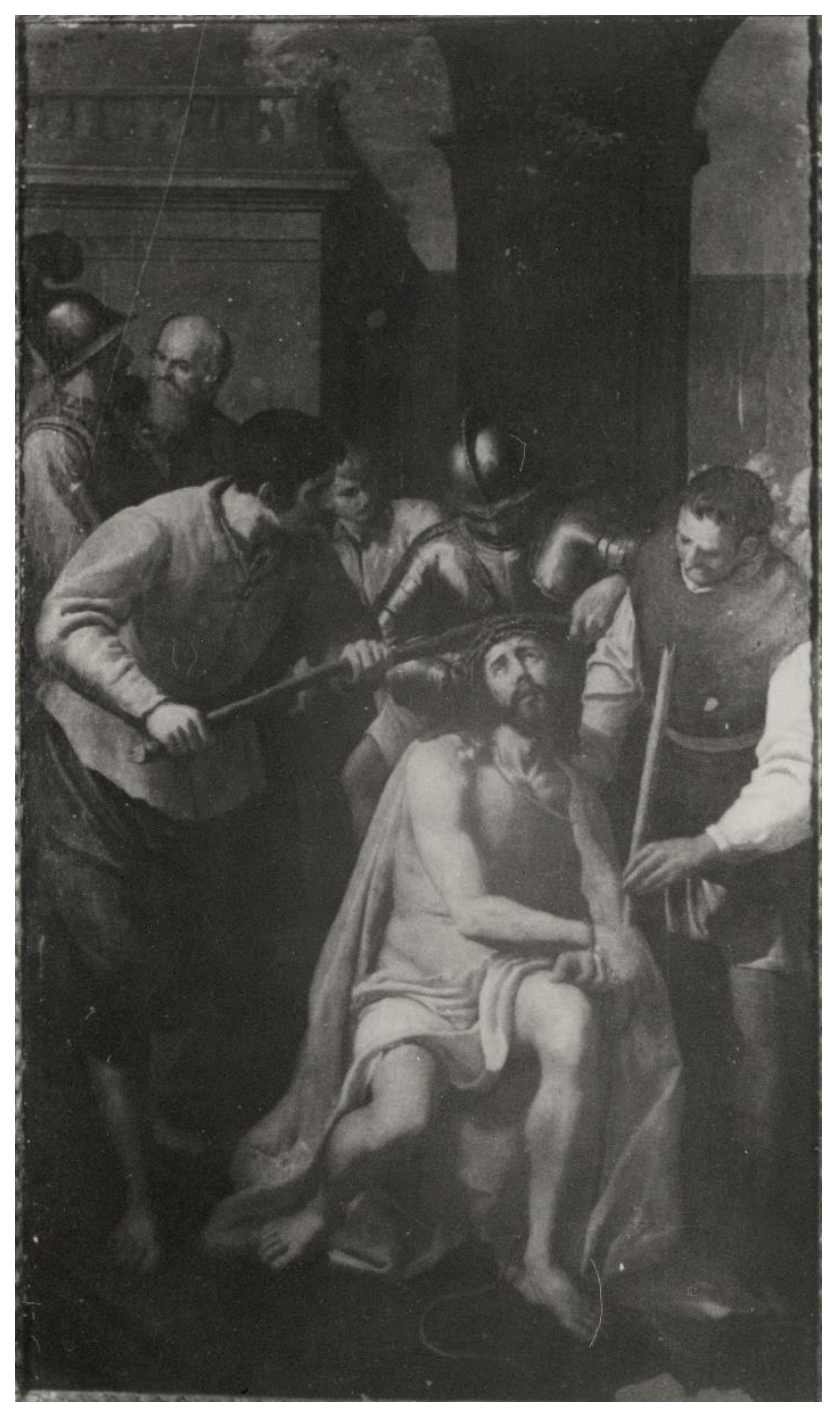

Fig. 3. Atribuido a Jusepe Leonardo, Coronación de espinas, ca. 1625-1630, pintura en paradero desconocido. Fotografía: Madrid, (c) CSIC, Archivo del Centro de Ciencias Humanas y Sociales (inv. ATN/DAP/33).

columna de dos varas escasas de alto, correspondiente de ancho"85. Finalizada la reforma en 1786 y devuelta al menos una parte de su patrimonio a la iglesia de la Almudena, aparece la última mención a las pinturas en el inventario parroquial de 1793, que fue revisado en 1804 . Se cita en primer lugar "Otro también en lienzo de la Oración del Huerto de la misma altura que la antecedente [dos varas] y dos varas de ancho con caña dorada"86. Más adelante se recoge su pareja: "Otra de Nuestro Señor atado a la columna de dos varas escasas de alto correspondiente de ancho con su caña dorada lisa"87. En el último inventario de la iglesia, redactado en 1869 por el cura párroco de Santa María con motivo de la demolición del edificio, ya no se hace mención alguna a la pareja de cuadros $^{88}$.

85 Tarrero Alcón, Santa María, Apéndice: Inventario de traslación de bienes al convento de las Madres Bernardas del Santísimo Sacramento, 1777, n० 130.

86 Tarrero Alcón, Santa María, Apéndice: Inventario de 1793 y revisión de 1804, no 29.

87 Tarrero Alcón, Santa María, Apéndice: Inventario de 1793 y revisión de 1804, no 31.

88 Tarrero Alcón, Santa María, Apéndice: Inventario de 1869. 
Perdidas las pinturas de Leonardo, contamos con algunos testimonios de obras de su mano que nos acercan a las composiciones que pudo realizar en la Almudena. Mazón de la Torre dio a conocer en 1977 la existencia de dos lienzos con temas de la Pasión atribuidos a Jusepe Leonardo, una Flagelación de Cristo y una Coronación de espinas (Figs. 2 y 3), ya entonces en paradero desconocido, que dan buena muestra de la aproximación del artista a los mismos temas que se empleaban en los monumentos pascuales ${ }^{89}$. Ambas pinturas, seguramente pertenecientes a una serie más amplia sobre la Pasión de Cristo, se conocen únicamente por sendas fotografías procedentes del archivo del antiguo Instituto Diego Velázquez.

Los dos cuadros, fechados por Mazón de la Torre en la segunda mitad de la década de 1620, muestran algunos de los rasgos característicos de la producción de Leonardo, que podemos suponer cercanos a los que emplearía en los lienzos encargados para el monumento de 1633. Contrasta la mayor idealización del cuerpo y rostro de Cristo, -sin huir por ello de la plasmación del dolor-, con el aspecto vulgar y descuidado de los sayones, que visten ropas holgadas y remangadas que recuerdan claramente a las indumentarias de tipo español representadas por otros artistas coetáneos como Diego Polo y Pedro Orrente en sus pinturas y dibujos, tema que ha sido estudiado por Benito Navarrete ${ }^{90}$.

El canon alargado y la posición de la figura que azota a Cristo, a la izquierda del cuadro de la Flagelación, traen a la memoria otras obras de Leonardo, especialmente la Degollación de san Juan Bautista del Museo Nacional del Prado (P-2229) ${ }^{91}$. Ambos personajes, encargados del martirio de Cristo y de san Juan Bautista respectivamente, comparten una misma construcción anatómica y una idéntica disposición de las extremidades, encontrándose entre las representaciones de mayor expresividad de toda la pintura de Leonardo. Esta postura de la figura del verdugo, con una pierna flexionada hacia adelante y los brazos en alto, ya fue ensayada por Leonardo en el lienzo con el tema del Martirio de Santiago del retablo de Cebreros (Ávila), su encargo más temprano documentado hasta la fecha, datado en $1625^{92}$. En el caso de la escena de la Flagelación, contribuye a acentuar su dramatismo la pronunciada torsión del cuerpo de Cristo hacia la derecha, actitud que adopta obligado ante la fuerza ejercida por sus verdugos. Este recurso de Leonardo, con un marcado énfasis en la violencia de los sayones que sujetan o golpean a Cristo, fue empleado de forma muy similar por otros artistas de la escuela madrileña con los que sin duda mantuvo contacto el pintor. Es el caso de las versiones al óleo y sobre papel realizadas en los mis-

\footnotetext{
89 Mazón de la Torre, Jusepe Leonardo, pp. 224-228 y 356; Torner Marco, Jusepe Leonardo, pp. 68 y 113. 90 Las ropas de estas pinturas de Leonardo recuerdan a las utilizadas por Diego Polo en varios de sus lienzos y dibujos, relacionados estos últimos con la indumentaria y el estilo de las figuras de Pedro Orrente por Benito Navarrete Prieto, I segni nel tempo. Dibujos españoles de los Uffizi, (Madrid-Florencia: Fundación Mapfre-Gallerie degli Uffizi, 2016), pp. 29 y 203.

91 Mazón de la Torre, Jusepe Leonardo, p. 79; Torner Marco, Jusepe Leonardo, pp. 71 y 117.

92 Mazón de la Torre, Jusepe Leonardo, pp. 204-224, en especial pp. 211-214; Torner Marco, Jusepe Leonardo, pp. 65-68, en especial p. 66. Para todas las obras de Leonardo citadas en este artículo véase también Angulo Íñiguez y Pérez Sánchez, Historia de la pintura española, pp. 78-103.
} 


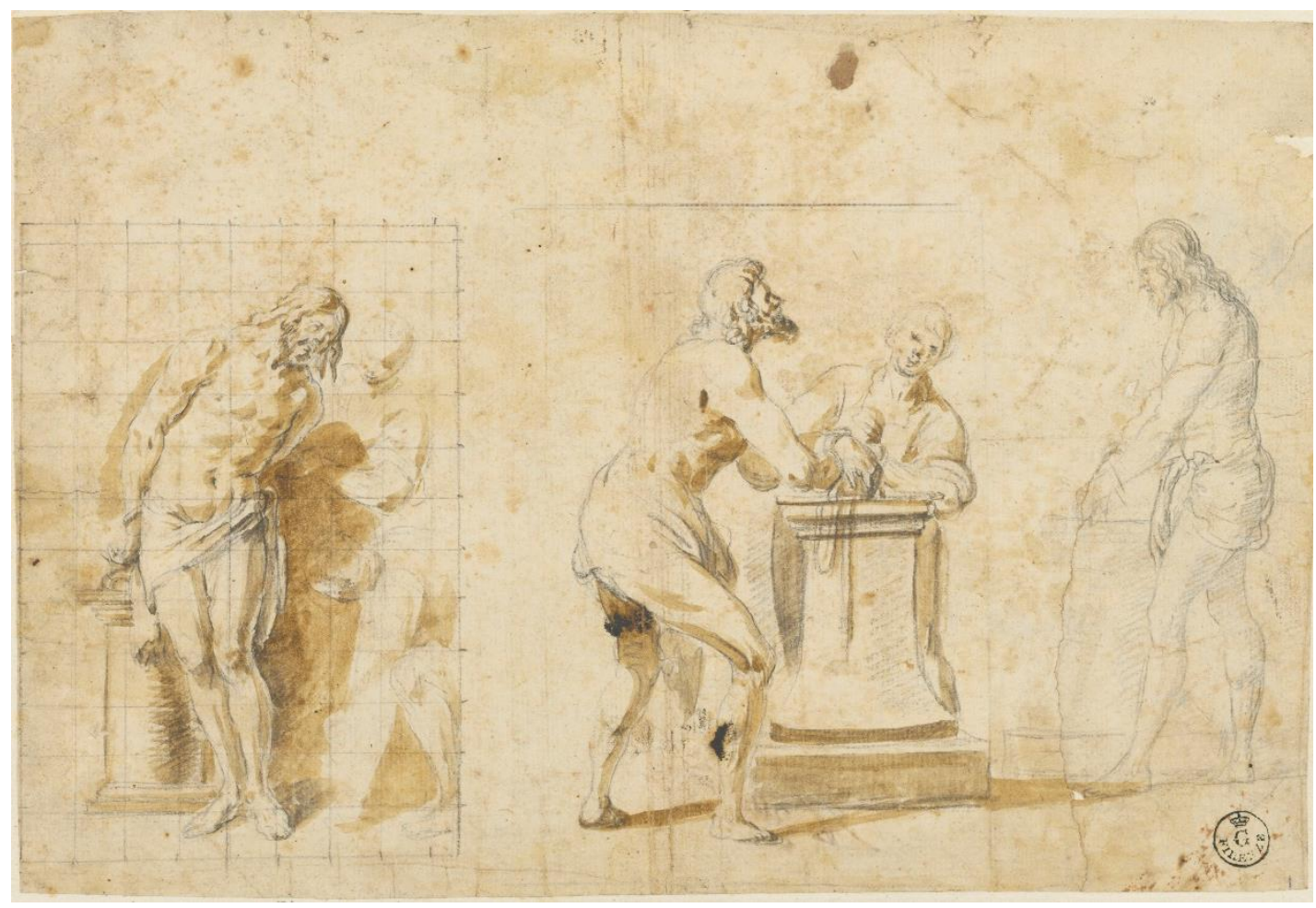

Fig. 4. Atribuido a Jusepe Leonardo, Flagelación de Cristo, 190 x 280 mm., ca. 1625-1630. Florencia, () Gallerie degli Uffizi (inv. 9082 F).

mos años por Vicente Carducho (principalmente Nueva York, The Apelles Collection y Florencia, Gallerie degli Uffizi, inv. 10201 S), que pudieron servir de modelo para otros pintores más jóvenes de su entorno ${ }^{93}$, con los que Carducho compartía encargos en los principales proyectos decorativos de palacio.

En relación con este tema iconográfico, destaca especialmente la reciente atribución a Leonardo por Benito Navarrete de un dibujo que representa la Flagelación de Cristo, fechado por el autor hacia 1625-30 (inv. 9082 F) (Fig. $4)^{94}$. Conservado en los Uffizi, este dibujo preparatorio tiene la particularidad de contar con la cuadricula a lápiz para ser traspasado a una pintura exenta, o bien a un lienzo destinado a un monumento de Semana Santa como el que hemos documentado en el año 1633 del mismo tema. En efecto, la compleja decoración de monumentos implicaba una importante organización del trabajo, con el diseño de las gradas, columnas, arcos y escenas de la Pasión que cubrían la totalidad de las estructuras de madera, unos preparativos que generarían amplios corpus de dibujos, buena parte de los cuales seguramente se han perdido o no han sido identificados como tales al desaparecer en la mayoría de los casos las pinturas definitivas a las que dieron lugar.

Pero el dibujo de los Uffizi, además del motivo de la Flagelación de Cristo, presenta una vista de perfil de Cristo atado a la columna y una figura de Cristo con las manos atadas, también de perfil. La presencia de tres estudios

\footnotetext{
93 Navarrete Prieto, I segni nel tempo, pp. 167-168, no 64, donde el autor apunta al fuerte impacto que causó esta iconografía de Carducho sobre otros artistas como Jusepe Leonardo.

94 Navarrete Prieto, I segni nel tempo, p. 191, (Fig. 129).
} 
de tema similar en la misma hoja, con una vista frontal, otra de perfil derecho y otra de perfil izquierdo, hacen que tampoco deba descartarse la posibilidad de que se trate de un dibujo preparatorio para una escultura, trabajo en el que, como hemos visto, el pintor participó junto al escultor Manuel Pereira en la iglesia de la Almudena al menos en una ocasión. En caso de encontrarnos ante un dibujo para una escultura, se ampliarían aún más las funciones de Leonardo en este campo, no únicamente encargado de su policromado sino también implicado en el proceso de creación del diseño original, siguiendo un canon en la representación de Cristo muy parecido al empleado en sus pinturas.

\section{Conclusión}

Los diferentes pagos realizados por la fábrica de Santa María a Jusepe Leonardo, entre 1632 y 1639, nos permiten incorporar un nuevo nombre a la nómina de artistas de la escuela madrileña que se dedicaron a la decoración de monumentos de Semana Santa. Frente a la relativa riqueza de noticias sobre la segunda mitad del siglo XVII en Madrid, con artistas como Sebastián de Benavente y José de Churriguera inmersos en el diseño y decoración de estas construcciones, no contábamos con documentación similar para la primera mitad del siglo, en la que desde ahora Jusepe Leonardo ocupa un puesto relevante en la pintura de estas arquitecturas.

Con respecto a la biografía de Leonardo, su labor como decorador de arquitectura efímera enriquece el abanico de especialidades artísticas que practicó, en estricta contemporaneidad con la creación de algunas de sus obras más reconocidas, como los cuadros de batallas para el Salón de Reinos del Buen Retiro. Si tenemos en cuenta los nuevos datos aportados en este artículo, junto con los que ya conocíamos sobre su dedicación a la pintura mural, podemos vislumbrar un artista con amplios conocimientos técnicos que le permitieron afrontar numerosos y muy distintos proyectos decorativos en la década de 1630. Esta acumulación de encargos en los años treinta del siglo XVII, junto con las menciones explícitas a las tareas de sus ayudantes que hemos localizado en los documentos, demuestran que Jusepe Leonardo contó con un amplio taller. Solo gracias a la colaboración de un buen número de aprendices y oficiales pudo Leonardo hacer frente a la pintura de cuadros de batallas, series de retratos de reyes, vistas de sitios reales, encargos de pintura mural y la decoración sistemática de monumentos pascuales, además de su participación en retablos como el de la actual catedral de Getafe, antigua iglesia parroquial de la Magdalena, o el de la iglesia de La Torre de Esteban Hambrán (Toledo), una actividad importante que se concentra en los mismos años.

Por su parte, la fábrica de la Almudena demostró un gran interés en la celebración de la Semana Santa, que se materializó en la construcción de su monumento, tarea a la que dedicó notables sumas de dinero a lo largo del siglo XVII, con un claro descenso de los recursos económicos empleados a 
medida que avanza la centuria siguiente. El auge de este monumento se produce en paralelo con la gran importancia cortesana que fue adquiriendo el templo de la Almudena, especialmente durante la primera mitad del siglo XVII, momento en que empieza a disfrutar del progresivo patrocinio de la corona. Como hemos visto, para sus principales encargos artísticos, la fábrica de Santa María recurrió a pintores del entorno cortesano como Alonso Cano, Diego Polo o el propio Leonardo. El perfecto conocimiento de este último por parte de la iglesia de Santa María explica su elección como primera opción para hacerse cargo de la pintura del Milagro del pozo de su retablo mayor en 1638, que finalmente no llegaría a realizar. Este hecho, junto con los pagos de pinturas para el monumento pascual, el policromado de estatuas y la reparación ocasional con cera de partes de esculturas, atestiguan la estrecha vinculación de Jusepe Leonardo con la desaparecida iglesia de la Almudena. Para ella realizaría en 1633 dos pinturas que, a pesar de haberse perdido por el deterioro que sufrían los monumentos de Semana Santa, podemos añadir al catálogo de sus temas representados: una Oración en el huerto, de la que no contamos por el momento con ejemplos que puedan ilustrar sobre su aspecto, y una Flagelación de Cristo que sería cercana al cuadro de su mano conocido únicamente a través de fotografía antigua, y al dibujo del mismo tema conservado en los Uffizi. 
Bibliografía:

Agulló Cobo 1978: Mercedes Agulló Cobo, Documentos sobre escultores, entalladores y ensambladores de los siglos XVI al XVIII, (Valladolid: Universidad de Valladolid, 1978).

Agulló Cobo 1978: Mercedes Agulló Cobo, "Manuel Pereira: aportación documental", Boletín del Seminario de Estudios de Arte y Arqueología, 44, (1978), pp. 257-278. (En web: https://dialnet.unirioja.es/servlet/articulo?codigo=2691247, consultado: 6 de febrero de 2021).

Agulló Cobo 1981: Mercedes Agulló Cobo, Más noticias sobre pintores madrileños de los siglos XVI al XVII, (Madrid: Ayuntamiento de Madrid, 1981).

Agulló Cobo 2006: Mercedes Agulló Cobo, Documentos para la historia de la pintura española, (Madrid: Fundación de Apoyo a la Historia del Arte Hispánico, 2006), vol. 3.

Angulo Íñiguez y Pérez Sánchez 1983: Diego Angulo Íñiguez y Alfonso Emilio Pérez Sánchez, Historia de la pintura española. Escuela madrileña del segundo tercio del siglo XVII, (Madrid: Consejo Superior de Investigaciones Científicas, Instituto Diego Velázquez, 1983).

Aterido Fernández 1995: Ángel Aterido Fernández, "Una nueva obra de José de Churriguera: el monumento de Semana Santa del Monasterio de la Encarnación", Anales del Instituto de Estudios Madrileños, 35, (1995), pp. 19-32.

Aterido Fernández 2002: Ángel Aterido Fernandez, "Alonso Cano y la alcoba de su majestad: la serie regia del Alcázar de Madrid", Boletín del Museo del Prado, 20, 38, (2002), pp. 9-36. (En web: https://www.museodelprado.es/aprende/boletin/alonso-cano-y-la-alcoba-de-su-majestad-laserie/ed262f78-ccf1-44d0-a724-0c1040090bf3, consultado: 6 de febrero de 2021).

Barrio Moya 2003: José Luis Barrio Moya, "Sebastián de Benavente y el monumento de Semana Santa del convento de Agustinas Recoletas de Santa Isabel en Madrid", Recollectio: annuarium historicum augustinianum, 25-26, (2002-2003), pp. 199-206. (En https://dialnet.unirioja.es/servlet/articulo?codigo $=6020431$, consultado: 6 de febrero de 2021).

Bartolomé García 2003: Fernando R. Bartolomé García, "Patrimonio recuperado: el monumento de Semana Santa de la Iglesia de Heredia", Akobe, 4, (2003), pp. 64-68.

Bonet Correa 1993: Antonio Bonet Correa, "La arquitectura efímera del Barroco en España", Norba, 13, (1993), pp. 23-70. (En web: https://dialnet.unirioja.es/servlet/articulo?codigo=107477, consultado: 6 de febrero de 2021). 
Bosch i Ballbona y Dorico i Alujas 1992: Joan Bosch i Ballbona y Carles Dorico i Alujas, "El monument de Setmana Santa de la catedral de Barcelona, de 1735", D'art, 17, (1992), pp. 253-260. (En web: https://www.raco.cat/index.php/Dart/article/view/100348, consultado: 6 de febrero de 2021).

Calvo Ruata y Lozano López 2004: José Ignacio Calvo Ruata y Juan Carlos Lozano López, "Los monumentos de Semana Santa en Aragón (siglos XVIIXVIII)", Artigrama, 19, (2004), pp. 95-137. (En web: http://www.unizar.es/artigrama/pdf/19/2monografico/03.pdf, consultado: 6 de febrero de 2021).

Caturla 1947: María Luisa Caturla, "Los retratos de Reyes del Salón Dorado en el antiguo Alcázar de Madrid", Archivo español de arte, 20, 77, (1947), pp. $1-10$.

Caturla 1947: María Luisa Caturla, Pinturas, frondas y fuentes del Buen Retiro, (Madrid: Revista de Occidente, 1947).

Caturla 1960: María Luisa Caturla, "Cartas de pago de los doce cuadros de batallas para el Salón de Reinos del Buen Retiro", Archivo español de arte, 33, 132, (1960), pp. 333-356.

Collar de Cáceres 1995: Fernando Collar de Cáceres, "Jusepe Leonardo en el retablo de La Torre de Esteban Hambrán", Archivo español de arte, 68, 269, (1995), pp. 1-16.

Cruz Valdovinos 2002: José Manuel Cruz Valdovinos, "Encargos y clientes de Alonso Cano en la corte de Felipe IV", en Alonso Cano. La modernidad del siglo de oro español, (Madrid: Fundación Santander Central Hispano, 2002), pp. 73-89.

Cruz Yábar 2013: Juan María Cruz Yábar, El arquitecto Sebastián de Benavente (1619-1689) y el retablo cortesano de su época, tesis doctoral, Universidad Complutense, (Madrid: 2013). (En web: https://eprints.ucm.es/id/eprint/23414/1/T34807.pdf, consultado: 6 de febrero de 2021).

Cruz Yábar 2018: Juan María Cruz Yábar, "El milagro del pozo de Alonso Cano para el retablo de Santa María de la Almudena. Documentos inéditos", Boletín del Museo del Prado, 36, 54, (2018), pp. 48-60. (En web: https://www.museodelprado.es/aprende/boletin/el-milagro-del-pozo-de-alonso-cano-para-el/ff16bf12b4f2-1b7d-b5d3-1126794a4a0a, consultado: 6 de febrero de 2021).

Echeverría Goñi 1990: Pedro Luis Echeverría Goñi, "Los monumentos o perspectivas en la escenografía del siglo XVIII de las grandes villas de la Ribera estellesa", Príncipe de Viana, 51, 190, (1990), pp. 517-532. (En web: https://dialnet.unirioja.es/servlet/articulo?codigo $=15875$, consultado: 6 de febrero de 2021).

Esteban Lorente 1976: Juan Francisco Esteban Lorente, "La capilla de San Marcos y el monumento de Semana Santa de La Seo de Zaragoza", Cuadernos de investigación: Geografía e historia, 2, 1, (1976), pp. 97-104. 
(En web: https://publicaciones.unirioja.es/ojs/index.php/cigh/article/view/1907, consultado: 6 de febrero de 2021).

García Hernández 1989: José Antonio García Hernández, "Las imágenes escultóricas del monumento de la catedral de Sevilla en la renovación de 1688-1689", Atrio, 1, (1989), pp. 43-60. (En web: https://www.upo.es/revistas/index.php/atrio/article/view/3415/2672, consultado: 6 de febrero de 2021).

García Hernández 1990: José Antonio García Hernández, "El montaje del monumento eucarístico de la catedral de Sevilla en 1692", Atrio, 2, (1990), pp. 71-80. (En web: https://www.upo.es/revistas/index.php/atrio/article/view/3404/2661, consultado: 6 de febrero de 2021).

García Rey 1931: Verardo García Rey, "Artistas madrileños al servicio del Arzobispado de Toledo", Revista de la biblioteca, archivo y museo, 29, (1931), pp. 76-87. (En http://www. memoriademadrid.es/buscador. php?accion=VerFicha\&id=29747\&num id=8\&num total=71, consultado: 6 de febrero de 2021).

González Bravo 2016: Sara González Bravo, "En torno a los monumentos de Semana Santa. El Barroco en Navarra", Príncipe de Viana, 77, 265, (2016), pp. 641-660. (En web: https://revistas.navarra.es/index.php/PV/article/view/852/441, consultado: 6 de febrero de 2021).

González Suárez 1988: Fernando González Suárez, "Las pinturas del monumento de Semana Santa de Beade", Porta da aira, 1, (1988), pp. 121129. (En web: https://dialnet.unirioja.es/servlet/articulo?codigo=2015617, consultado: 6 de febrero de 2021).

González Suárez 1989: Fernando González Suárez, "Notas sobre las pinturas del monumento de Semana Santa en Beade", Porta da aira, 2, (1989), pp. 233-235. (En web: https://dialnet.unirioja.es/servlet/articulo?codigo=2015604, consultado: 6 de febrero de 2021).

Gutiérrez García-Brazales 1982: Manuel Gutiérrez García-Brazales, Artistas y artífices barrocos en el Arzobispado de Toledo, (Toledo: Obra Cultural de la Caja de Ahorros Provincial de Toledo, 1982).

Ibáñez Abella 2019: María Belén Ibáñez Abella, "Los cantorales y la librería del Coro en la Seo de Zaragoza: nuevas aportaciones documentales para el estudio de la reforma de la capilla de San Marcos y el monumento, a comienzos del siglo XVIII", Artigrama, 34, (2019), pp. 357-390. (En web: http://www.unizar.es/artigrama/pdf/34/3varia/03.pdf, consultado: 6 de febrero de 2021).

Lamas-Delgado 2016: Eduardo Lamas-Delgado, "Monumento de Semana Santa de la catedral de Toledo, h. 1668", en I segni nel tempo. Dibujos españoles de los Uffizi, dir. Benito Navarrete Prieto, (Madrid-Florencia: Fundación Mapfre-Gallerie degli Uffizi, 2016), pp. 208-209.

López-Yarto Elizalde 2006: Amelia López-Yarto Elizalde, "El esplendor de la liturgia eucarística: el monumento y el arca del Jueves Santo de la catedral 
de Toledo", en Estudios de platería: San Eloy 2006, coord. Jesús Rivas Carmona, (Murcia: Universidad de Murcia, 2006), pp. 379-400. (En web: https://digital.csic.es/bitstream/10261/16214/1/P\%C3\%A1ginas\%20de\%20san-eloy-2006.pdf, consultado: 6 de febrero de 2021).

Madrazo 1872: Pedro de Madrazo, Catálogo descriptivo e histórico del Museo del Prado de Madrid, (Madrid: Imprenta y estereotipia de M. Rivadeneyra, 1872). (En web: https://www.museodelprado.es/aprende/biblioteca/bibliotecadigital/fondo/catalogo-descriptivo-e-historico-del-museo-del/3fa3ce41-0da5-4466-8103-

c7f441b3f598? searchid=495cafea-7ed7-4051-aabb-46fd10087c18, consultado: 6 de febrero de 2021).

Martín Montero 1952: María del Carmen Martín Montero, "Jusepe Leonardo y Manuel Pereira", Archivo español de arte, 25, 98, (1952), p. 170.

Mazón de la Torre 1975: María Ángeles Mazón de la Torre, "En torno a Jusepe Leonardo", Archivo español de arte, 48, 190-191, (1975), pp. 266-270.

Mazón de la Torre 1977: María Ángeles Mazón de la Torre, Jusepe Leonardo y su tiempo, (Zaragoza: Institución Fernando el Católico, 1977).

Mazón de la Torre 1982: María Ángeles Mazón de la Torre, "Escultores madrileños del siglo XVII: Juan Bautista Garrido", en Miscelánea de arte, (Madrid: Consejo Superior de Investigaciones Científicas, Instituto Diego Velázquez, 1982), pp. 137-139.

Mercader Saavedra 2009: Santiago Mercader Saavedra, "Descubiertas las esculturas del antiguo monumento de Semana Santa de la catedral de Barcelona (1735)" en Congreso Internacional Imagen Apariencia, 2008, dirs. María Concepción de la Peña Velasco, Manuel Pérez Sánchez, María del Mar Albero Muñoz, María Teresa Marín Torres y Juan Miguel González Martínez, (Murcia: Universidad de Murcia, 2009). (En web: https://digitum.um.es/digitum/bitstream/10201/42844/1/CongresoImagen47.pdf, consultado: 6 de febrero de 2021).

Monzón Gasca 2015: Juan Monzón Gasca, "Un proyecto de realidad aumentada para la difusión de la capilla del monumento de La Seo de Zaragoza: aplicación de técnicas de documentación gráfica y geométrica basadas en la ingeniería inversa", Ars \& Renovatio, 3, (2015), pp. 166-191. (En web: https://dialnet.unirioja.es/servlet/articulo?codigo $=5171365$, consultado: 6 de febrero de 2021).

Morales 1993: Alfredo J. Morales, "Un dibujo del monumento de la catedral de Sevilla por Lucas Valdés", Laboratorio de Arte, 6, (1993), pp. 157-167. (En web: http://institucional.us.es/revistas/arte/06/07\%20morales.pdf, consultado: 6 de febrero de 2021).

Morte García 1986: María del Carmen Morte García, "Monumentos de Semana Santa en Aragón en el siglo XVI", Artigrama, 3, (1986), pp. 195-214. 
Navarrete Prieto 2016: Benito Navarrete Prieto dir., I segni nel tempo. Dibujos españoles de los Uffizi, (Madrid-Florencia: Fundación Mapfre-Gallerie degli Uffizi, 2016).

Nicolau Castro 1989: Juan Nicolau Castro, "Precisiones documentales sobre el monumento barroco de la catedral de Toledo y un dibujo madrileño del último tercio del siglo XVII", Archivo español de arte, 62, 246, (1989), pp. 216-219.

Novo Sánchez 2013: Francisco Xavier Novo Sánchez, "El monumento de Semana Santa de la catedral de Tui carte efímero?", en Las artes y la arquitectura del poder, coord. Víctor Mínguez Cornelles, (Castellón de la Plana: Universitat Jaume I, 2013), pp. 2653-2672.

Palomino [1724] 1947: Antonio Palomino de Castro y Velasco, El museo pictórico y escala óptica, III, El parnaso español pintoresco laureado, (Madrid: Aguilar, 1947).

Pascual Chenel y Rodríguez Rebollo 2017: Álvaro Pascual Chenel y Ángel Rodríguez Rebollo, "¿A la sombra de Velázquez? Los pintores cortesanos durante el reinado de Felipe IV", en La corte de Felipe IV (1621-1665). Reconfiguración de la Monarquía católica, coords. José Martínez Millán y Manuel Rivero Rodríguez, (Madrid: Polifemo, 2017), t. 3, vol. 4, pp. 26432730.

Pérez Sánchez 1969: Alfonso Emilio Pérez Sánchez, "Diego Polo", Archivo español de arte, 42, 165, (1969), pp. 43-54.

Portús Pérez 1992: Javier Portús Pérez, "Alonso Cano: la creación de una leyenda", en Veintitrés biografías de pintores, coord. Francisco Calvo Serraller, (Madrid: Mondadori-Fundación Amigos del Museo del Prado, 1992), pp. 319-344.

Puerta Rosell 2003: María Fernanda Puerta Rosell, "Noticias sobre la vida y obra de Sebastián de Benavente: monumento de Semana Santa para el convento de Santa Isabel de Madrid", Anales del Instituto de Estudios Madrileños, 43, (2003), pp. 553-566.

Quesada 2001: María Jesús Quesada, "El monumento de Semana Santa de la catedral de Segovia", Estudios segovianos, 44, 101, (2001), pp. 303-320.

Saltillo 1953: Marqués del Saltillo, "Artistas madrileños (1592-1850)", Boletín de la Sociedad Española de Excursiones, 57, (1953), pp. 137-243.

Tarrero Alcón 2007: María Cristina Tarrero Alcón, Santa María la Real de la Almudena: dos siglos y medio de arte e historia (1638-1868), tesis doctoral inédita, Universidad Complutense, (Madrid: 2007).

Torner Marco 2007: Ramón Torner Marco, Jusepe Leonardo. Un pintor bilbilitano en la Corte de Felipe IV, (Zaragoza: Institución Fernando el Católico, 2007). (En web: https://ifc.dpz.es/recursos/publicaciones/29/06/ ebook.pdf, consultado: 6 de febrero de 2021). 
Vizcaíno Villanueva 2005: María Ángeles Vizcaíno Villanueva, El pintor en la sociedad madrileña durante el reinado de Felipe IV, (Madrid: Fundación Universitaria Española, 2005).

Zorrozua Santisteban 2002: Julen Zorrozua Santisteban, "El monumento de Semana Santa de Santa María de Bermeo (Bizkaia)", Ondare, 21, (2002), pp. 257-272. (En web: http://www.eusko-ikaskuntza.eus/es/publicaciones/el-monumento-desemana-santa-de-santa-maria-de-bermeo-bizkaia/art-9509/, consultado: 6 de febrero de 2021).

Recibido: 8/02/2021

Aceptado: $28 / 04 / 2021$ 